\title{
Conceito, tratamento e causas da halitose: um estudo transversal com discentes de
}

\author{
odontologia \\ Concept, treatment and causes of halitosis: a cross-sectional study with dentistry students \\ Concepto, tratamiento y causas de la halitosis: un estudio transversal con estudiantes de \\ odontologia
}

Recebido: 10/10/2021 | Revisado: 14/10/2021 | Aceito: 15/10/2021 | Publicado: 17/10/2021

\author{
Anna Clara da Silva Dias \\ ORCID: https://orcid.org/ 0000-0001-9511-9554 \\ Faculdade Patos de Minas, Brasil \\ E-mail: anna.00778@alunofpm.com.br \\ Juliana Cristina Ribeiro \\ ORCID: https://orcid.org/ 0000-0003-3104-8595 \\ Faculdade Patos de Minas, Brasil \\ E-mail: julliana.cribeiro@outlook.com \\ Marcelo Dias Moreira de Assis Costa \\ ORCID: https://orcid.org/ 0000-0001-9148-3674 \\ Universidade Federal de Uberlândia, Brasil \\ E-mail: marcelodmac@yahoo.com.br \\ Victor da Mota Martins \\ ORCID: https://orcid.org/ 0000-0001-6631-6161 \\ Centro Universitário de Patos de Minas, Brasil \\ E-mail: victortag@hotmail.com \\ Cláudia Maria de Oliveira Andrade \\ ORCID: https://orcid.org/ 0000-0003-4529-8106 \\ Faculdade Patos de Minas, Brasil \\ E-mail: claudiamoacd@yahoo.com.br \\ Lia Dietrich \\ ORCID: https://orcid.org/ 0000-0001-7887-8591 \\ Universidade Federal dos Vales do Jequitinhonha e Mucuri, Brasil \\ E-mail: dietrichlia.ld@gmail.com
}

\begin{abstract}
Resumo
A halitose é uma condição de etiologia multifatorial conhecida popularmente como um odor desagradável que é exalado pela cavidade oral e nasal. O objetivo deste trabalho é avaliar o nível de conhecimento de graduandos e pós graduandos, sobre a definição de halitose, tratamento e diagnóstico dos diferentes tipos existentes. A metodologia utilizada constitui-se de um estudo transversal através de um questionário on-line, onde são extraídos dados que possibilitem identificar se os discentes têm conhecimento adequado sobre o diagnóstico, causas e possíveis tratamentos da halitose. Observou-se, após a análise dos dados, que $74 \%$ dos participantes eram do sexo feminino. Dentre os resultados encontrados, podemos destacar: $74 \%$ considerou a halitose uma doença, $65 \%$ afirmam saber diagnosticar a halitose. Em relação às causas da halitose: $60 \%$ responderam que são de origem bucais, $41 \%$ fisiológicas, $51 \%$ patológicas e sistêmicas, $43 \%$ assinalaram todas as opções, e $51 \%$ disseram ser de causas multifatoriais. Sobre as melhores formas de tratamento: $79 \%$ considerou a opção de higiene bucal e o uso de fio dental, e de evitar alimentos como cebola e alho, 57\% acham que existe aparelhos para o diagnóstico de halitose, e $86 \%$ pressupõem que a saliva compromete o mau hálito. Pode-se afirmar que a halitose é uma condição que afeta milhares de pessoas mundialmente, e apesar de muitos discentes de Odontologia acreditarem que sabem sobre o assunto, através da pesquisa, foi verificado uma falta de conhecimento científico sobre o mesmo, necessitando de novas ações para melhora nas informações.
\end{abstract}

Palavras-chave: Halitose; Odontologia; Diagnóstico; Etiologia.

\begin{abstract}
Halitosis is a condition with a multifactorial etiology, popularly known as an unpleasant smell that is exhaled through the oral and nasal cavity. The objective of this work is to evaluate the level of knowledge of undergraduates and graduate students about the definition of halitosis, treatment and diagnosis of the different types that exist. The methodology used consists of a cross-sectional study through an online questionnaire, where data are extracted that make it possible to identify whether students have adequate knowledge about the diagnosis, causes and possible treatments for halitosis. A literature review was carried out for theoretical knowledge and preparation of the electronic
\end{abstract}


questionnaire. After analyzing the data, it was observed that $74 \%$ of the participants were female. Among the results found, it is possible to highlight: $74 \%$ considered halitosis a disease, $65 \%$ claim to know how to diagnose halitosis. Regarding the causes of halitosis: $60 \%$ answered that it is oral origin, $41 \%$ physiological, $51 \%$ pathological and systemic, $43 \%$ checked all the options, and 51\% answered it had multifactorial causes. About the best forms of treatment: $79 \%$ considered the option of oral hygiene and the use of dental floss, and avoiding foods such as onions and garlic, 57\% think there are devices for diagnosing halitosis, and $86 \%$ assume that saliva compromises bad breath. It can be said that halitosis is a condition that affects thousands of people worldwide, and although many dentistry students believe they know about the subject, through research, a lack of scientific knowledge on the subject was verified, requiring new actions to improve the information.

Keywords: Halitosis; Dentistry; Diagnosis; Etiology.

\section{Resumen}

La halitosis es una condición de etiología multifactorial, conocida popularmente como olor desagradable que se exhala por la cavidad oral y nasal. El objetivo de este trabajo es evaluar el nivel de conocimiento de los estudiantes de pregrado y posgrado sobre la definición de halitosis, tratamiento y diagnóstico de los diferentes tipos que existen. La metodología utilizada consiste en un estudio transversal a través de un cuestionario online, donde se extraen datos que permiten identificar si los estudiantes tienen un conocimiento adecuado sobre el diagnóstico, las causas y los posibles tratamientos de la halitosis. Se realizó una revisión de la literatura para el conocimiento teórico y elaboración del cuestionario electrónico. Después de analizar los datos, se observó que el 74\% de los participantes eran mujeres. Entre los resultados encontrados, podemos destacar: el 74\% consideraba la halitosis una enfermedad, el $65 \%$ afirma saber diagnosticar la halitosis. En cuanto a las causas de la halitosis: 60\% respondió que son de origen oral, $41 \%$ fisiológicas, $51 \%$ patológicas y sistémicas, $43 \%$ marcaron todas las opciones y $51 \%$ dijeron tener causas multifactoriales. Sobre las mejores formas de tratamiento: el 79\% consideró la opción de la higiene bucal y el uso de hilo dental, y evitar alimentos como la cebolla y el ajo, el 57\% piensa que existen dispositivos para el diagnóstico de halitosis, y el $86 \%$ asume que la saliva compromete el mal aliento. Se puede decir que la halitosis es una condición que afecta a miles de personas en todo el mundo, y aunque muchos estudiantes de odontología creen conocer el tema, a través de la investigación se verificó una falta de conocimiento científico sobre el tema, requiriendo nuevas acciones para mejorar la información.

Palabras clave: Halitosis; Odontología; Diagnóstico; Etiología.

\section{Introdução}

Halitose deriva do latim, em que halitos significa ar expirado e osis uma alteração patológica o que pode ser definida como "hálito desagradável" que pode ser exalado pela boca, pelas cavidades nasais, pelos seios da face e pela faringe (Ferreira, 2016; Mourão, 2014). É uma condição de etiologia multifatorial que pode ser causada por problemas bucais, sistêmicos, psicológicos (Andrade, \& Cerqueira-Leite, 2015; Leandrin, Boeck, Ricci, \& Mourão, 2014; Silveira, 2019). Alguns hábitos como fumar, consumo de bebida alcoólica, ingestão recente de alguns tipos de alimentos e a utilização de soluções para bochecho com álcool na composição podem estar relacionados com a halitose (Ferreira, 2016; Mourão, 2014; Silveira, 2019).

As causas de origem sistêmica podem ser doenças otorrinolaringológicas e respiratórias (faringite, tonsilite, sinusite, amidalite, rinites, bronquites, abscessos, corpo estranho na cavidade nasal ou sinusal, neoplasias),de origem digestivas, (síndromes de má absorção, doença do refluxo gastroesofágico, esofagite, hérnia hiatal, infecção por Helicocabter pylori, neoplasias, erupção gástrica, úlcera duodenal e retenção alimentar) de alterações metabólicas como diabetes, alterações hormonais ou outras como insuficiência renal, trimetilaminúria, lesões tumorais (Bicak, 2018; Borges et al., 2018; Domingos et al., 2011; Falcão, 2005; Mourão, 2014; Leandrin et al., 2015; Prata \& Macedo, 2019; Rodrigues, 2009). Os problemas de halitose relacionados ao estômago são muito raros (Dal Rio, et al., 2007; Rodrigues, 2009).

A degradação de microrganismos na cavidade bucal é o principal motivo do mau odor na cavidade oral patológica (Dal Rio, Nicola, \& Teixeira, 2007; Ferreira, 2016; Mourão, 2014). Ocorrendo assim o metabolismo bacteriano de aminoácidos contendo enxofre (metionina, cistina e cisteína) e os compostos sulfurados voláteis (CSVs) são formados (Faber, 2009; Fagundes \& Oliveira, 2017; Ferreira, 2016; LeBel et al., 2017). A halitose tem sido correlacionada com a concentração de CSV produzidos que são liberados por bactérias predominantemente anaeróbias proteolíticas gram-negativas (Abreu, Domingos, \& Dantas, 2011; Ciarcia et al., 2019; Dal Rio et al., 2007; Rodrigues, 2009). 
A halitose pode ser classificada como: genuína, pseudo-halitose ou halitofobia (Broek, Feenstra, \& Baat, 2008; Fagundes \& Oliveira, 2017; Ferreira, 2016; Mourão, 2014; Pereira, Marcelo, André, \& Lousan, 2019; Prata \& Macedo, 2019; Silveira, 2019, Vasconcelos, Veloso, Cunha, \& Vasconcelos, 2011). A halitose genuína é subclassificada como fisiológica ou patológica sendo a fisiológica aquela sentida ao acordar, causada pela diminuição do fluxo salivar, degradação dos microrganismos durante o sono, ou jejum prolongado, dietas descontroladas, hábitos ou alimentação inadequada (Broek et al., 2008; Fagundes \& Oliveira, 2017; Ferreira; 2016; Pereira et al., 2019). A forma patológica pode ser de origem intra ou extrabucal (Bicak, 2018; Canever \& Nazário, 2019; Mourão, 2014; Pereira et al., 2019; Silveira, 2019; Torsten, GómezMoreno, \& Aguilar-Salvatierra, 2017). Já a pseudo-halitose ou halitofobia, é comum em pacientes que apresentam uma falsa percepção da presença do mau hálito, o psicológico do paciente acha que essa com halitose, algo imaginário (Bicak, 2018; Dal Rio et al., 2007; Domingos, Abreu, Dantas, \& Oliveira, 2011; Fagundes \& Oliveira, 2017; Leandrin et al., 2015; Mourão, 2014; Pereira et al., 2019).

A halitose na qualidade de vida de uma pessoa tem um reflexo enorme (Dal Rio, et al., 2007; Mourão, 2014; Rodrigues, 2009; Silveira, 2019). A maioria das pessoas que tem halitose não sabe, pois, o nariz acostuma com o cheiro produzido pelos compostos sulfurados, e são avisadas por pessoas próximas ou familiares, causando assim um constrangimento e extremo desconforto o que podem afetar a comunicação e as relações sociais (Associação Brasileira de Halitose [ABHA], 2008; Dal Rio, et al., 2007; Faber, 2009; Mourão, 2014; Silveira, 2019). Essas pessoas acabam se isolando, tentando mascarar o mau hálito, com o uso de elixir ou goma de mascar (Abreu et al., 2011; Broek et al., 2008; Dal Rio et al., 2007; Prata \& Macedo, 2019; Roldán, Herrera, \& Sanz, 2003). Mas é sabido que só irá funcionar momentaneamente, a pessoa com a halitose deve procurar um profissional para um correto diagnóstico e tratamento (Abreu et al., 2011; Borges et al., 2018; Canever \& Nazário, 2019; Silveira, 2019).

Existem inúmeras causas para a halitose (Abreu et al., 2011; Bicak, 2018; Borges et al., 2018; Dal Rio et al., 2007; Domingos, Abreu, Dantas, \& Oliveira, 2011; Faber, 2009; Fagundes \& Oliveira, 2017; Ferreira, 2016; Leandrin et al., 2015; Mourão, 2014; Prata \& Macedo, 2019; Pereira et al., 2019; Rodrigues, 2009; Silveira, 2019; Vasconcelos et al., 2011; Sombié et al., 2018). A maioria está relacionada à cavidade bucal e causas gerais, de origem sistêmica (Abreu et al., 2011; Borges et al., 2018; Dal Rio et al., 2007; Domingos et al., 2001; Faber, 2009; Fagundes \& Oliveira, 2017; Ferreira, 2016; Mourão, 2014; Pereira et al., 2019; Silveira, 2019; Prata \& Macedo, 2019). Segundo a literatura a halitose proveniente da cavidade oral é a mais prevalente em mais de $80 \%$ dos casos, principalmente, pela saburra lingual, gengivite e/ou periodontite (Abreu et al., 2011; Borges et al., 2018; Broek et al., 2008; Canever \& Nazário, 2019; Dal Rio, et al., 2007; Domingos et al., 2011; Leandrin et al., 2015; Mourão, 2014; - Pereira et al., 2019; Rodrigues, 2009 Sombié et al., 2018;Vasconcelos et al., 2011). Outras causas de origem local podem ser: processos cariosos, placa bacteriana, língua fissurada, peças protéticas mal adaptadas, xerostomia, doenças peri-implantares, pericoronarite, ulcerações da mucosa, alterações na composição da saliva (Abreu et al., 2011; Bicak, 2018; Borges et al., 2018; Dal Rio, et al., 2007; Domingos et al., 2011; Fagundes \& Oliveira, 2017; Leandrin et al., 2015; Mourão, 2014; Pereira et al., 2019; Prata \& Macedo, 2019; Rodrigues, 2009; Vasconcelos et al., 2011).

Devido às suas causas multifatoriais a halitose é de difícil diagnóstico (Bicak, 2018; Borges et al., 2018; Canever \& Nazário, 2019; Kraether Neto, Schmidt Maas, \& Pellicioli, 2019; Leandrin et al., 2015; Mourão, 2014; Prata \& Macedo, 2019). Entretanto, os métodos mais utilizados são os testes organoléptico, ou seja, inalação direta do ar proveniente da boca do paciente, e a cromatografia gasosa ou analisadores portáteis de CSVs, aparelhos que examinam amostras do ar expirado (Dal Rio et al., 2007; Fagundes \& Oliveira, 2017; Kraether Neto et al., 2019; Rodrigues, 2009; Silveira, 2019; Vasconcelos et al., 2011). O teste organoléptico é o mais utilizado, se o odor for proveniente do ar exalado pela boca a causa mais provável será a bucal ou faríngea; se o odor for proveniente das narinas a causa mais provável está localizada nas narinas e nos seios maxilares, e em outros casos se os odores provêm do nariz e da boca provavelmente será de origem sistêmica (Silveira, 2019). 
Contudo, esse teste possui desvantagens porque não é objetivo, tem baixa reprodutibilidade e não quantifica os CSVs e a saturação do olfato do examinador (Falcão, 2005; Ferreira, 2016; Prata \& Macedo, 2019; Silveira, 2019).

A halitose tem tratamento e existem pessoas capacitadas para tratá-la, embora ainda não exista a especialidade halitose e, portanto, não há especialistas nessa área (ABHA, 2009). Deve-se primeiro identificar a possível causa da halitose (Dal Rio et al., 2007; Ferreira, 2016). Depois deve-se diminuir os compostos voláteis de enxofre e as outras substâncias com intervenções mecânicas e químicas na cavidade bucal (Domingos et al., 2011; Faber, 2009; Fagundes \& Oliveira, 2017). O tratamento básico recomendado para halitose inclui a remoção mecânica da saburra de língua com escovas de dentes ou raspadores de língua, uso de fio dental diariamente, intensificação da escovação e intervenção química com o uso de enxaguatórios antimicrobianos que contenham, por exemplo, clorexidina e cloreto de cetilperidínio que podem reduzir as bactérias produtoras de compostos sulfurados na língua (Borges et al., 2018; Canever \& Nazário, 2019; Domingos et al., 2011; Fagundes \& Oliveira, 2017; Ferreira, 2016; Faber, 2009; Vasconcelos et al., 2011).

Visto que a Halitose é um tema que aparentemente se mostra simples para a maioria das pessoas, mas infelizmente boa parte dos profissionais de saúde não tem o conhecimento mínimo e não sabem as causas da halitose para diagnosticar o problema. A população também não tem consciência dos fatores que podem causar ou manter a halitose. Esse artigo tem como objetivo conhecer os diferentes tipos de halitose e investigar, através de uma pesquisa se graduandos e pós-graduandos de Odontologia sabem como diagnosticar, tratar e melhorar o convívio social do paciente com Halitose.

\section{Metodologia}

A Metodologia da presente pesquisa se constitui de um estudo transversal através de um questionário on-line elaborado pelas pesquisadoras desse estudo, com base na literatura relatada, no qual foram extraídos dados que possibilitaram identificar se graduandos e pós-graduandos de Odontologia, sabem sobre diagnóstico, tratamento, e causas de halitose. Para isso utilizou-se a pesquisa exploratória e descritiva, com uma abordagem qualitativa-quantitativa, com o uso de fontes primárias e secundárias através do método indutivo. O protocolo de pesquisa foi aprovado pelo Comitê de Ética e Pesquisa com Seres Humanos da Faculdade Patos de Minas (FPM) com o número do parecer: 4.372.163.

O campo selecionado para a realização da pesquisa foi através de questionários para graduandos e pós graduandos em Odontologia de faculdades públicas e privadas das regiões Centro-Oeste e Sudeste do Brasil, no entanto o link estava sendo divulgado e qualquer instituição poderia participar do estudo. A fase de coleta ocorreu no período de 27 de janeiro de 2021 a 3 de maio de 2021. Para o recrutamento dos participantes, foi feita a divulgação exclusivamente de forma virtual através do envio de e-mails para o e-mail de algumas instituições, a fim de informar aos alunos de graduação sobre a existência desta pesquisa.

Atendendo ao público-alvo, foi utilizado o programa "Calcular e Converter", disponível no Google online, que segue o link: https://calculareconverter.com.br/calculo-amostral/. Utilizou-se o intervalo de confiança de $95 \%$ e margem de erro de 5\%. Um mínimo de 150 voluntários foi estimado, no entanto, 100 respostas ao questionário foram aceitas

O questionário foi preenchido de forma digital através da plataforma Google Forms (Google; Mountain View, CA, EUA), com o seguinte link: https://docs.google.com/forms/d/1uPNW_mFjHIt-IV5AY5GnVEwpMYmF6yO5 goP4uRGc3AM/edit. As questões abordadas no questionário estão sequenciadas nos resultados deste artigo.

Os critérios de inclusão basearam-se em pessoas que no questionário marcaram que desejavam participar da pesquisa e responder todas às perguntas. Já o critério de exclusão estabelecido foi em pessoas que no questionário marcaram que não desejavam participar da pesquisa, mesmo respondendo todas as perguntas. 


\section{Revisão de Literatura}

\subsection{Conceito Halitose}

Halitose conhecida mundialmente devido seu mau cheiro exalado pela cavidade oral, nasal (Borges et al., 2018; Ferreira, 2016; Prata \& Macedo, 2019). Uma condição de etiologia multifatorial que pode ser causada por problemas sistêmicos, bucais, psicológicos, que afetam ambos sexos em algum momento da vida (Abreu et al., 2011; Borges et al., 2018; Domingos et al., 2011; Ferreira, 2016). Alguns hábitos como fumar, consumo de bebida alcoólica, ingestão de alguns tipos de alimentos e a utilização de soluções para bochecho com álcool na composição hálito pode estar relacionados com a halitose (Abreu et al., 2011; Domingos et al., 2011; Ferreira, 2016; Leandrin et al., 2015).

Muitas referências foram feitas com o termo halitose, no Antigo Testamento da Bíblia, foi encontrado um registro onde Jó (19:17) lamenta-se “O mau Hálito é intolerável à minha mulher...” ensinamentos litúrgicos Judeus alega-se que marido poderia se divorciar-se da sua mulher caso descobrisse que a mesma teria mau Hálito (Ferreira, 2016; Rodrigues, 2009). Hipócrates relatou também que "Se a gengiva se tornar saudável novamente, o odor ofensivo se esvai". (Falcão, 2005). No entanto, essa preocupação insiste nos dias atuais (Falcão, 2005).

O ar inalado é constituído aproximadamente por $78 \%$ de azoto (designação antiga para nomear nitrogênio) $21 \%$ de oxigênio 0,096\% de árgar de 0,04\% de dióxido de carbono, Hélio, água e outros gases (Mourão, 2014). O mau hálito se desenvolve por um mecanismo de deterioração da matéria orgânica levando a produção de substâncias que causam o mau cheiro (Borges et al., 2018; Dal Rio et al., 2007). A língua é considerada como um dos maiores nichos microbianos da cavidade bucal (Abreu et al., 2011; Bicak, 2018; Borges et al., 2018; Broek et al., 2008; Domingos et al., 2011; Leandrin et al., 2015; Rodrigues, 2009). Produz CSVs, sendo um dos principais causadores da Halitose, na sua composição contém o enxofre (Canever \& Nazário, 2019; Falcão, 2005; Mourão, 2014). Os CSVs mais importantes envolvidos são o sulfeto de hidrogênio $(\mathrm{H} 2 \mathrm{~S})$, metilmercaptano $(\mathrm{CH} 3 \mathrm{SH})$ e o dimetil sulfeto $(\mathrm{CH} 3) 2 \mathrm{~S}$, produzidos principalmente por bactérias anaeróbias gramnegativas (Domingos et al., 2011; Rodrigues, 2009; Silveira, 2019).

\subsection{Classificação e divisão}

A halitose pode ser classificada como: genuína, pseudo-halitose ou halitofobia (Prata \& Macedo, 2019; Silveira, 2019; Vasconcelos et al., 2011). A halitose genuína é subclassificada como fisiológica ou patológica sendo a fisiológica aquela sentida ao acordar, causada pela diminuição do fluxo salivar e degradação dos microrganismos durante o sono, ou jejum extenso, dietas descontroladas, hábitos ou alimentação inadequada (Silveira, 2019).

A forma patológica pode ser de origem intra ou extrabucal (Borges et al., 2018; Domingos et al., 2011; Rodrigues, 2009). Intra Oral causada por: língua saburrosa; gengivite; estomatite; periodontite; pericoronarite; alveolite; cárie em atividade; polpa dentária necrótica exposta; ulceração oral; xerostomia; hábitos (respiração bucal, tabagismo, etilismo); sinusite; bronquite; diabetes; úlcera duodenal; anomalias craniofaciais (fenda palatina); neoplasia (Ciarcia et al., 2019; Pereira et al., 2019; Vasconcelos et al., 2011). Já a extrabucal, pode ter causa pneumológica, gastrenterológica, metabólica, alimentar, infecciosa, farmacológica, neoplásica (Ferreira, 2016; Pereira et al., 2019; Rodrigues, 2009).

A pseudo-halitose, é comum em pacientes que apresentam uma falsa percepção da presença do mau hálito, a pessoa acredita ser portadora, porém não reflete a realidade (Canever \& Nazário, 2019; Leandrin et al., 2015; Mourão, 2014). Halitofobia não tem comprovação de halitose social ou física, conhecida como halitose imaginária (Prata \& Macedo, 2019; Vasconcelos et al., 2011).

\subsection{Etiologia e causas}

De ocorrência mundial, a halitose pode afetar ambos os sexos, com uma incidência maior em adultos, têm sua 
etiologia multifatorial (Abreu et al., 2011; Domingos et al., 2011; Ferreira, 2016; Leandrin et al., 2015). A degradação de microrganismos na cavidade bucal é o principal motivo do mau odor na cavidade oral patológica (Borges et al., 2018; Mourão, 2014; Rodrigues, 2009). Ocorrendo assim o metabolismo bacteriano de aminoácidos contendo enxofre e os compostos sulfurados voláteis (CSVs) são formados (Borges et al., 2018; Canever \& Nazário, 2019). A halitose tem sido correlacionada com a concentração de CSV produzidos que são liberados por bactérias anaeróbias proteolíticas gram-negativas (Borges et al., 2018; Canever \& Nazário, 2019; Fagundes \& Oliveira, 2017; Kraether Neto et al., 2019; Mourão, 2014).

A microbiota normal da boca é constituída por cocos, bacilos Gram - positivos e Gram-negativo, é altamente importante para a cavidade oral (Ferreira, 2016; Mourão, 2014). Quando a microbiota está associada à halitose, a prevalência é de anaeróbios proteolíticos Gram - negativos (Borges et al., 2018; Dal Rio et al., 2007; Fagundes \& Oliveira, 2017; Ferreira, 2016; Mourão, 2014).

A Saburra lingual é um dos principais causadores da halitose relacionada com a pouca salivação (Abreu et al., 2011; Borges et al., 2018; Domingos et al., 2011; Falcão, 2005; Ferreira, 2016). É esbranquiçada devido aos substratos, e fica localizada na parte posterior do dorso da língua (Abreu et al., 2011; Borges et al., 2018; Domingos et al., 2011; Ferreira, 2016; Prata \& Macedo, 2019).

As pessoas portadoras de Diabetes estão mais propensas a desenvolver a halitose, pois há possibilidade de produção de corpos cetônicos expirados em altos níveis de glicose e pela ausência de insulina (Abreu et al., 2011; Dal Rio, et al., 2007; Ferreira, 2016; Prata \& Macedo, 2019). Pode causar boca seca, aumento dos CSVs e causar até mesmo a xerostomia (Dal Rio et al., 2007; Ferreira, 2016).

Doenças gastrointestinais estão relacionadas muito com o refluxo gastroesofágico, síndrome de má absorção (Dal Rio et al., 2007; Fagundes \& Oliveira, 2017). Já a cirrose hepática altera o metabolismo das proteínas (Dal Rio et al., 2007; Rodrigues, 2009).

Quando ingerimos bebidas alcoólicas ou passamos por um momento de estresse há uma redução do fluxo salivar, desidratando a mucosa oral permitindo um aumento da descamação epitelial (Abreu et al., 2011; Dal Rio, et al., 2007; Domingos et al., 2011; Rodrigues, 2009). Com os medicamentos também pode haver a redução desse fluxo salivar levando a uma possível xerostomia e o aparecimento da halitose (Borges et al., 2018; Domingos et al., 2011; Ferreira, 2016; Leandrin et al., 2015).

O tabagismo está também diretamente ligado com mau cheiro, o indivíduo que faz uso do tabaco tem o odor aumentado devido o próprio odor do tabaco, podendo permanecer esse mau cheiro dias após o seu uso (Domingos et al., 2011; Ferreira, 2016; Leandrin et al., 2015). O hábito de fumar predispõe a hipossalivação e doenças periodontais resultando a halitose (Dal Rio et al., 2007; Ferreira, 2016; Rodrigues, 2009).

Alguns alimentos mais comuns como alho, cebola são absorvidos pela corrente sanguínea e o odor é levado para os pulmões onde serão exalados no ar, podendo ser eliminados com a escovação, fio dental e enxaguatórios bucais (Domingos et al., 2011; Ferreira, 2016, Prata \& Macedo, 2019; Silveira, 2019).

$\mathrm{Na}$ doença periodontal às bactérias presentes entram em contato com essa gengiva inflamada alterando a microflora bucal, ou seja, a doença deixa o indivíduo mais vulnerável (Abreu et al., 2011; Domingos et al., 2011; Ferreira, 2016; Silveira, 2019).

\subsection{Diagnóstico}

Devido às suas causas multifatoriais a halitose é de difícil diagnóstico dessa forma não existem protocolos clínicos pré estabelecidos (Silveira, 2019). Mas existem alguns métodos para a sua detecção, entre eles existem formas subjetivas (como por exemplo mensuração/teste organoléptico) e objetivas (como a cromatografia gasoso e o halímetro) para a análise da 
halitose (Canever \& Nazário, 2019; Kraether Neto et al., 2019; Leandrin et al., 2015; Pereira et al., 2019; Vasconcelos et al., 2011). Dentre essas técnicas algumas não identificam a halitose propriamente dita, mas sim os seus componentes químicos (Mourão, 2014).

Para se ter sucesso no tratamento dependerá de um bom e correto diagnóstico, associando a terapias adequadas, em alguns casos há a necessidade de uma abordagem multifatorial e racional para que se tenha bons resultados e consequentemente melhora a saúde da cavidade oral (Mourão, 2014).

O primeiro passo para um correto diagnóstico é uma boa e detalhada anamnese (Broek et al., 2008; Ferreira, 2016; Mourão, 2014; Rodrigues, 2009). Deve ser feita através de um questionário contendo as queixas do paciente, história médica e dentária, incluir informações sobre a dieta, os costumes sociais, condição psicológica e emocional do paciente (Broek et al., 2008; Ferreira, 2016; Mourão, 2014; Rodrigues, 2009). Seguido de um bom exame clínico intra-oral (observar fatores que podem contribuir para a condição, inspeção em especial para a língua e tecidos periodontais que podem ser focos de proliferação de microrganismos causadores da halitose) e extra oral (como inspeção do trato respiratório superior) (Broek et al., 2008; Ferreira, 2016; Mourão, 2014; Rodrigues, 2009). É de grande valia a execução do teste salivar, pois a sua redução ou a hipossalivação do paciente poderá contribuir para a formação de biofilme lingual, que será capaz de causar a halitose (Mourão, 2014; Rodrigues, 2009).

Alguns métodos são mais utilizados para diagnósticos, dentre eles a mensuração/teste organoléptico, cromatografia gasosa e halímetro (Broek et al., 2008; Silveira, 2019; Rodrigues, 2009).

\subsection{Exame / Mensuração / Teste Organoléptico}

É um dos testes mais utilizados, trata-se de uma técnica subjetiva que tem como objetivo a avaliação da halitose através de uma abordagem simples e confiável (Mourão, 2014). É um método de avaliação que dependerá da capacidade olfatória do examinador, analisa-se o ar expelido pela boca ou pela cavidade nasal do examinado (Dal Rio et al., 2007; Fagundes \& Oliveira, 2017).

O paciente deve ir ao dentista no o período que se sente com o hálito mais forte, e antes da realização de qualquer teste deve aconselhar o examinando que não utilize qualquer artifício que mascare ou elimine o mau hálito, como colutório, escova dentária com ou sem dentifrícios pelo período de duas horas antes do teste; não consumir alimentos que possuem certo odor característico; evitar o consumo de álcool e tabaco próximos ao exame; não usar perfume, gomas, pastilhas, sprays aromatizados no dia da avaliação (Dal Rio et al., 2007; Ferreira, 2016; Mourão, 2014; Pereira et al., 2019; Prata \& Macedo, 2019; Rodrigues, 2009). Já o examinador não deve consumir café, chá ou sumo e evitar o uso de tabaco, e atentar-se às condições climáticas que diminuam a sensibilidade (Dal Rio et al., 2007; Pereira et al., 2019; Rodrigues, 2009).

Esse método de diagnóstico consiste em pedir ao paciente que inspire profundamente o ar pelas cavidades nasais e expire pela cavidade bucal, enquanto o examinador analisa o ar expelido, em uma distância de 10 a $20 \mathrm{~cm}$ (varia de literatura), e registra a medição numa escala específica (Dal Rio et al., 2007; Falcão, 2005; Ferreira, 2016; Mourão, 2014; Prata \& Macedo, 2019; Rodrigues, 2009). Podendo avaliar a presença ou ausência de odor e quantificar sua intensidade (Dal Rio et al., 2007; Falcão, 2005; Ferreira, 2016; Mourão, 2014; Prata \& Macedo, 2019; Rodrigues, 2009).

Segundo Rosenberg et al. (1991) e Sombié et al. (2018), a escala de odor pode ser classificada de 0 a 5, sendo: $0=$ sem odor perceptível; 1 = odor dificilmente perceptível; 2 = odor perceptível; 3 = odor moderado; 4 = odor forte; 5 = odor extremamente forte (Bicak, 2018; Falcão, 2005; Fagundes \& Oliveira, 2017; Ferreira, 2016; Kraether Neto et al., 2019; Pereira et al., 2019; Rodrigues, 2009).

As vantagens desse diagnóstico consistem em um baixo custo, não necessita de equipamento específico e detectam uma vasta gama de odores, visto que o nariz humano pode detectar mais de 10 mil odores (Falcão, 2005; Ferreira, 2016; 
Pereira et al., 2019); como desvantagem pode destacar a subjetividade do teste, difícil quantificação dos CSVs, a saturação do olfato do examinador e a dificuldade de reprodutibilidade, além de possuir risco potencial de infecção cruzada (Mourão, 2014; , Falcão, 2005; Ferreira, 2016; Pereira et al., 2019; Prata \& Macedo, 2019; Silveira, 2019). Com isso é recomendado que se utilize testes auxiliares para confirmar os resultados, com testes objetivos como o halímetro ou o teste de BANA (enzymathic method benzoyl-arginine-naphtylamida) (Dal Rio et al., 2007; Ferreira, 2016; Mourão, 2014; Rodrigues, 2009).

\subsection{Cromatografia Gasosa}

A Cromatografia Gasosa (CG), trata-se de uma artificio altamente objetivo, é o método mais confiável de diagnóstico da halitose (Dal Rio et al., 2007; Mourão, 2014; Prata \& Macedo, 2019; Vasconcelos et al., 2011). É fundamentado numa análise quantitativa dos componentes individuais dos CSV (H2S, CH3SH e (CH3)2S) presentes no mau hálito (Dal Rio et al., 2007; Mourão, 2014; Prata \& Macedo, 2019; Vasconcelos et al., 2011).

Para a realização deste recurso o paciente necessita de instrução de acordo com cada aparelho (Mourão, 2014). A medição é feita através de pico de leitura registrado (Mourão, 2014). E os resultados baseiam-se em leitura de números: até 100 o paciente não possui odor, de 100 até 180 apresenta um grau leve de halitose e acima de 250 indica halitose crônica (Mourão, 2014).

Dentre as vantagens da CG destaca-se a separação e determinação quantitativa de gases individuais e capacidade de medir concentrações extremamente baixas de gases (Bicak, 2018; Ferreira, 2016; Prata \& Macedo, 2019; Rodrigues, 2009; Silveira, 2019). Além disso, é possível detectar halitose de etiologia intraoral e extraoral (Ferreira, 2016; Mourão, 2014). Já as desvantagens consistem basicamente no aparelho: no custo elevado, pessoas especializadas para manipulá-lo e interpretá-lo em dimensões grandes (Bicak, 2018; Ferreira, 2016; 7, Prata \& Macedo, 2019; Rodrigues, 2009; Silveira, 2019).

\subsection{Halímetro}

É o aparelho mais utilizado para a monitorização de sulfeto, analisa a quantidade de enxofre presente no hálito (Mourão, 2014). Trata-se de um aparelho portátil, de fácil utilização. Um método rápido e objetivo para os valores de halitose (Mourão, 2014; Vasconcelos et al., 2011).

O halímetro é um monitor portátil com um visor digital que registra a quantidade de CSV por parte de bilhão (ppb) (Falcão, 2005; Ferreira, 2016). É mais sensível para o sulfeto de hidrogênio e metilmercaptana e quase insensível para o dimetil sulfeto (Ferreira, 2016).

Antes da realização desse exame os pacientes devem ser instruídos a não utilizar produtos que possam máscara ou eliminar a halitose como; uso de bebidas alcoólicas, fumo, colutórios, escovas dentais, dentifrícios, pastilhas, evitar perfumes, batons (Dal Rio et al., 2007; Ferreira, 2016; Mourão, 2014; Prata \& Macedo, 2019). E como o aparelho é sensível a compostos voláteis, ele deve ser calibrado para o ar de fundo antes de fazer qualquer teste (Mourão, 2014; Vasconcelos et al., 2011).

A medição deste método é feita através de uma prévia instrução ao paciente, ele deve manter a boca fechada de 3 a 5 minutos, depois o paciente insere um tubo descartável na cavidade bucal que está conectado ao halímetro enquanto ele respira pelo nariz (Bicak, 2018; Prata \& Macedo, 2019). No visor é gerado um valor médio em ppb, que corresponde às concentrações de CSVs na cavidade oral. Os resultados para a análise de halitose variam de acordo com cada fabricante (Ferreira, 2016; Mourão, 2014; Prata \& Macedo, 2019).

Os monitores de sulfeto possuem algumas vantagens, como o fato de serem portáteis, baixo custo e facilidade de manusear (Mourão, 2014). As desvantagens devem -se ao fato da limitação na detecção de alguns odores importantes da halitose e com isso, não é adequado para detectar a halitose de origem sistêmica (Falcão, 2005; Mourão, 2014). 


\subsection{Teste de Bana}

O teste BANA trata se de um teste enzimático complementar para a identificação de bactérias de origem periodontal que causam mau hálito, analisa-se a presença da enzima arginina hidrólase, utilizado como indicador da presença de microrganismos responsáveis por doenças periodontais (Leandrin et al., 2015; Mourão, 2014).

A sua principal desvantagem é a desse teste é que não determina o papel específico das diferentes espécies bacterianas na produção de halitose (Fagundes \& Oliveira, 2017). Está fortemente relacionado com a doença periodontal e a presença de saburra língua (Fagundes \& Oliveira, 2017).

Quando o teste do halímetro corresponde com um resultado negativo, o teste de BANA pode ser usado para acusar resultados positivos. Sugerindo que este teste pode ser usado como um complemento o halímetro (Dal Rio et al., 2007; Ferreira, 2016; Mourão, 2014).

\subsection{Tratamento}

Com um diagnóstico correto da principal causa etiológica da halitose, deve-se traçar um protocolo de tratamento, visando também um caráter multidisciplinar (Borges et al., 2018; Mourão, 2014).

O tratamento de sucesso da halitose consiste em diminuir os compostos voláteis de enxofre e outras substâncias desagradáveis, através de intervenções mecânicas e químicas, visto que a maioria das halitoses são de origem bucal (Faber, 2009; Fagundes \& Oliveira, 2017; Mourão, 2014; Rodrigues, 2009). Mas independente de qual seja o tipo de halitose, a higiene oral é indispensável para o êxito do tratamento (Mourão, 2014).

O cirurgião-dentista deve ficar atento a possíveis nichos de microrganismo como próteses, restaurações, mal adaptadas, lesões de cárie, doença periodontal (Mourão, 2014), fazendo em primeiro plano uma adequação do meio bucal seguida de explicações e instruções de higiene oral e também aconselhar o paciente sobre sua dieta (Canever \& Nazário, 2019; Mourão, 2014; Rodrigues, 2009).

As intervenções mecânicas são tipicamente: a intensificação da escovação, o uso do fio dental e a raspagem da superfície lingual (Borges et al., 2018; Faber, 2009; Fagundes \& Oliveira, 2017; Mourão, 2014; Prata \& Macedo, 2019; Pereira et al., 2019; Rodrigues, 2009; Vasconcelos et al., 2011).

As intervenções químicas estão relacionadas a redução de contagens de bactérias produtoras de halitose dentre elas pode -se citar uso de enxaguatórios antimicrobianos principalmente a base de clorexidina e cloreto de cetilpiridínio; dentifrícios a base de antimicrobianos, triclosan; óleos essências (Canever \& Nazário, 2019; Fagundes \& Oliveira, 2017; Faber, 2009; LeBel et al., 2017; Pereira et al., 2019). Contudo segundo a literatura essas intervenções não devem ser utilizadas por um longo período, pois podem causar danos aos tecidos orais (Róldan et al., 2003).

Um método utilizado pela indústria cosmética para mascarar odores e através de gomas, pastilhas e sprays (4). As gomas podem também estimular a produção de saliva (Canever \& Nazário, 2019; Pereira et al., 2019).

Recentemente um novo recurso terapêutico tem ganhado destaque na Odontologia, A terapia fotodinâmica antimicrobiana (aPDT) (Canever \& Nazário, 2019). A técnica trata-se do uso de um corante atóxico, chamado fotossensibilizador (FS), associada a uma fonte de luz de comprimento de onda específico na presença de oxigênio ambiental (laser de baixa potência), criando espécies reativas de oxigênio (ROC) que geram morte celular (Ciarcia et al., 2019). As vantagens desta abordagem são evitar resistência às bactérias alvo e danos aos tecidos adjacentes (Ciarcia et al., 2019). Essa técnica pode ser utilizada para a eliminação dos compostos sulfurados provenientes da língua (Canever \& Nazário, 2019; Ciarcia et al., 2019).

A halitose de origem sistêmica deve ser tratada com uma abordagem multidisciplinar (profissional dentista e médicos), visto que a causa etiológica provém de problema sistêmico. As áreas médicas mais relacionadas à halitose são a 
gastrenterologia e a otorrinolaringologia (Borges et al., 2018; Prata \& Macedo, 2019).

A halitofobia é o tipo de halitose mais difícil de ser tratado, pois o paciente precisa aceitar a ausência do odor proveniente da sua cavidade oral. O paciente deve ser encaminhado a um profissional de saúde capaz de ajudá-lo, como um psicólogo ou psiquiatra (Domingos et al., 2011; Fagundes \& Oliveira, 2017; Mourão, 2014; Rodrigues, 2009, Vasconcelos et al., 2011).

Em suma o tratamento halitose deve conter: orientação higiene e oral da dieta; tratamento dentário geral ou específico; e encaminhamento ou trabalhar de forma multidisciplinar com outros profissionais de saúde, quando for necessário (Mourão, 2014).

\section{Resultados}

Dos participantes, o gênero predominante foi o feminino com $74 \%$, o masculino com $25 \%$ e $1 \%$ indefinido conforme o Gráfico 1. Com a média de idade equivalente a 22,62.

Gráfico 1 - Distribuição de indivíduos classificados por gênero.

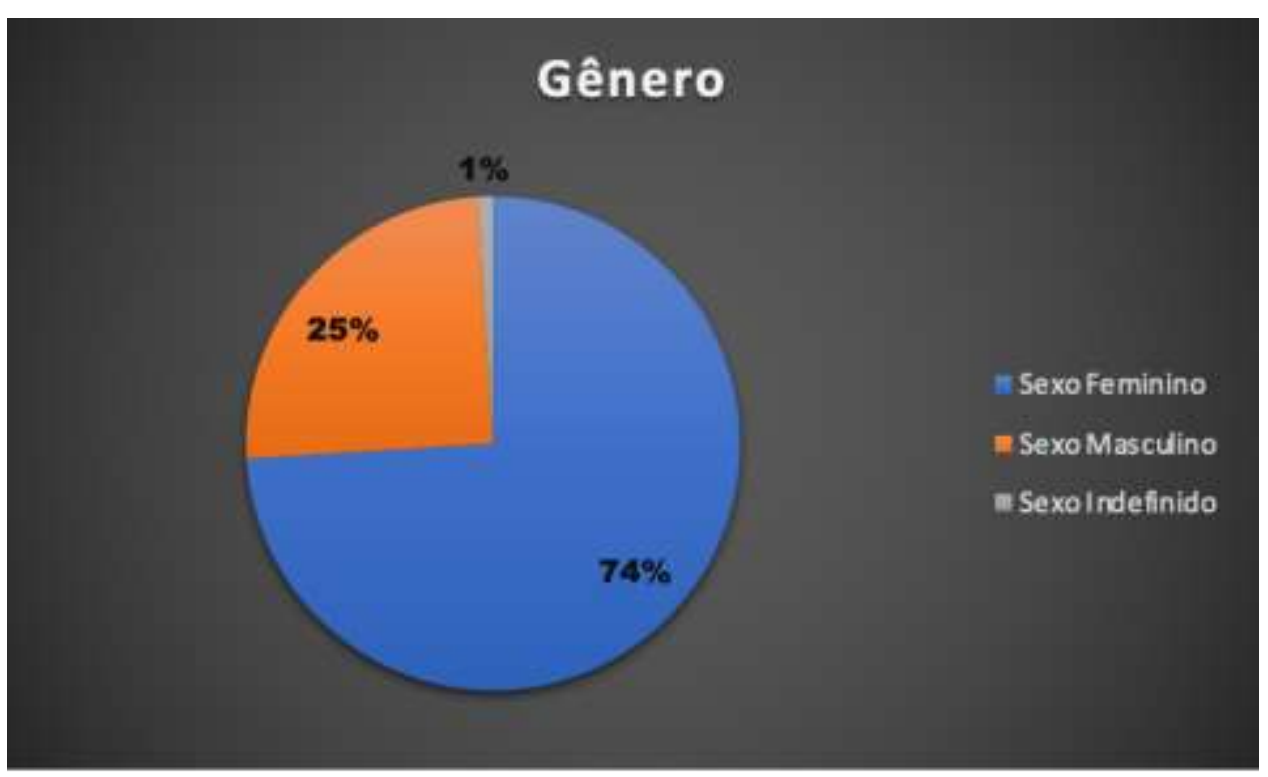

Fonte: Autores.

Nota-se a predominância do gênero masculino. A média de idade dos participantes equivale a 22,62.

As instituições participantes foram: Faculdade de Patos de Minas - FPM ( $\mathrm{n}=68)$, Centro Universitário de Patos de Minas (UNIPAM ( $\mathrm{n}=16)$ ), Universidade Federal de Uberlândia (UFU n= 9)), União de Negócios e Administração Ltda ( UNA de Bom Despacho $(n=1)$ ), Instituto Odontológico das Américas (IOA Brasília $(n=1)$ ), Newton Paiva $(n=1)$, Universidade de Itaúna (n=1), Centro Universitário do Maranhão (CEUMA (n=1)), Instituto de Qualificação Odontológico (IQO (n=1)), e um indivíduo que preferiu não identificar a instituição, conforme apresentado no Gráfico 2. 
Gráfico 2 - Disposição de participantes de acordo com a instituição de ensino.

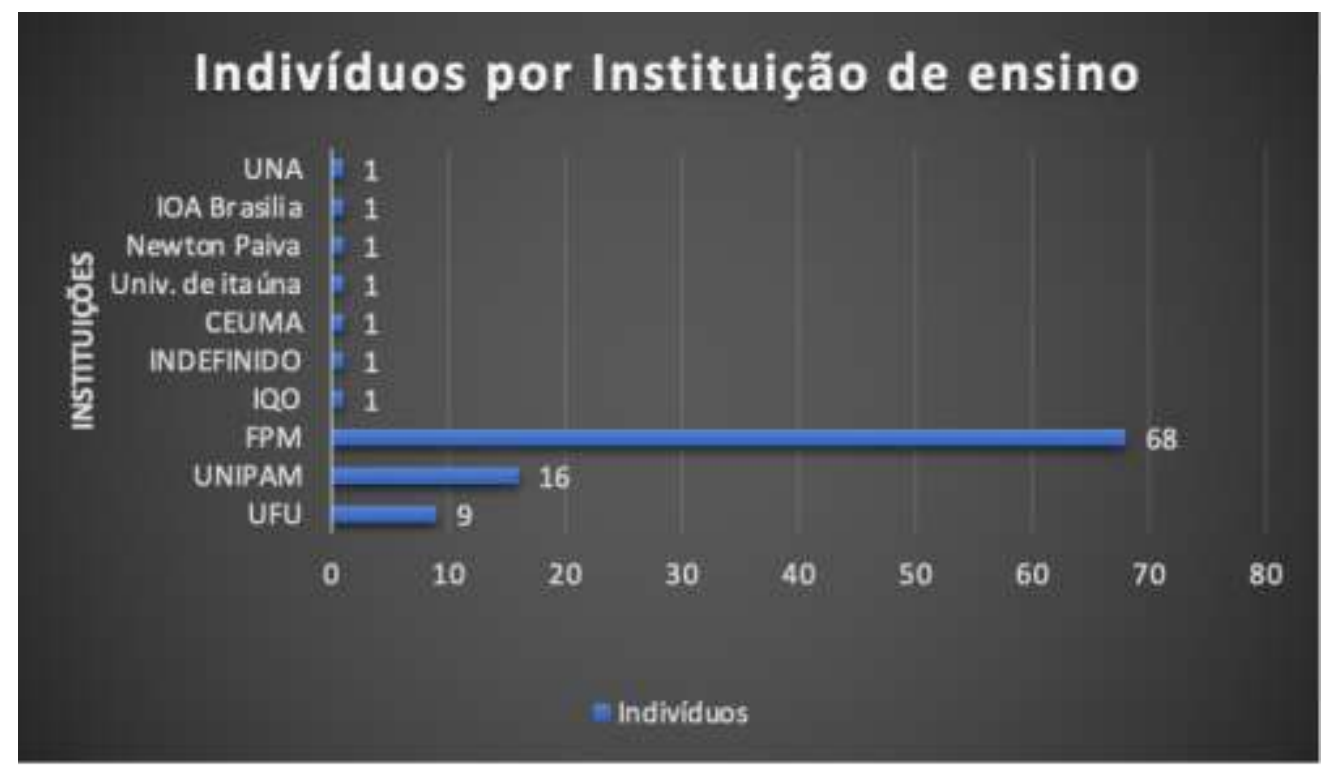

Fonte: Autores.

Desses 100 participantes, 91 informaram ser do curso de graduação em Odontologia e 9 da pós-graduação. No Gráfico 3 observa-se a distribuição dos indivíduos de graduação por instituição e no Gráfico 4 de pós-graduação por instituição. Já na Tabela 1, observa-se a distribuição dos indivíduos de pós-graduação referentes ao tipo de curso: lato sensu (endodontia, prótese fixa, estética e especialização) e stricto sensu (mestrado e doutorado) e ainda observa-se o período da graduação que os alunos estão cursando sendo do $1^{\circ}$ ao $10^{\circ}$ período.

Gráfico 3 - Distribuição alunos da graduação por instituição de ensino.

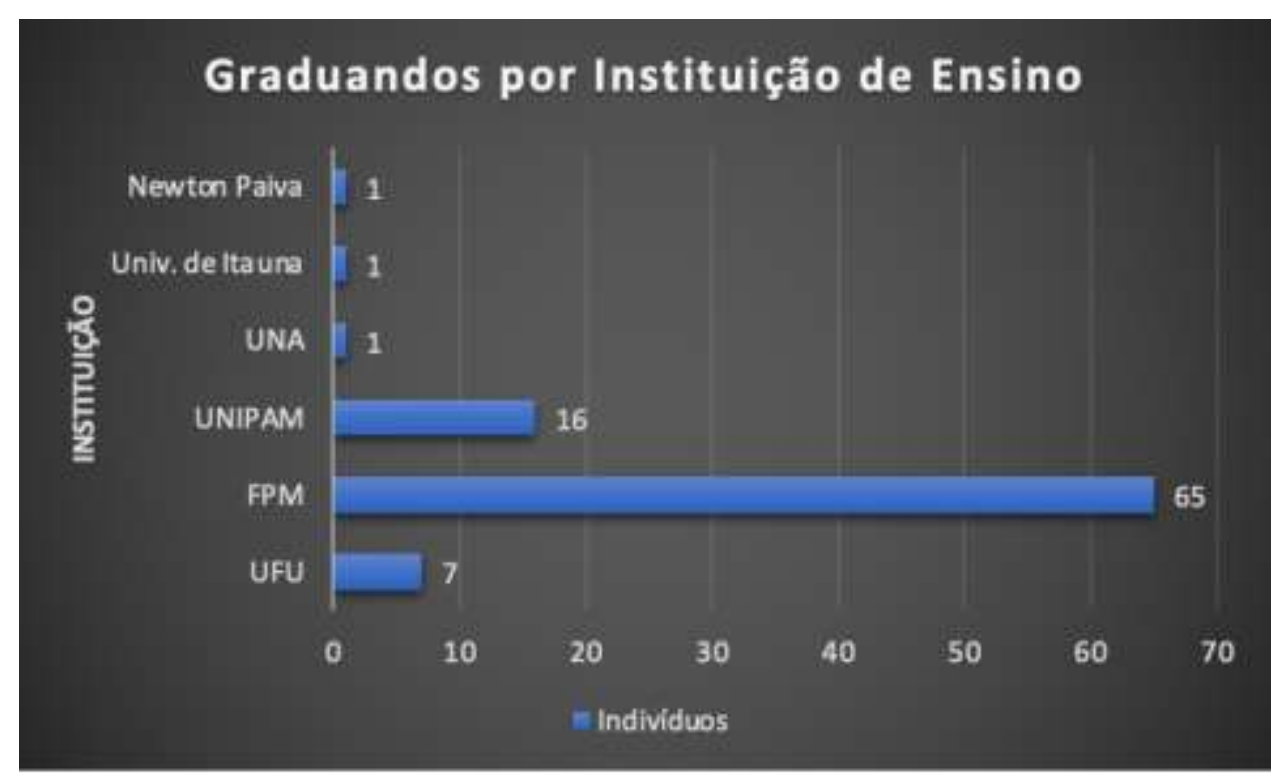

Fonte: Autores. 
Gráfico 4 - Distribuição alunos da pós-graduação por instituição de ensino.

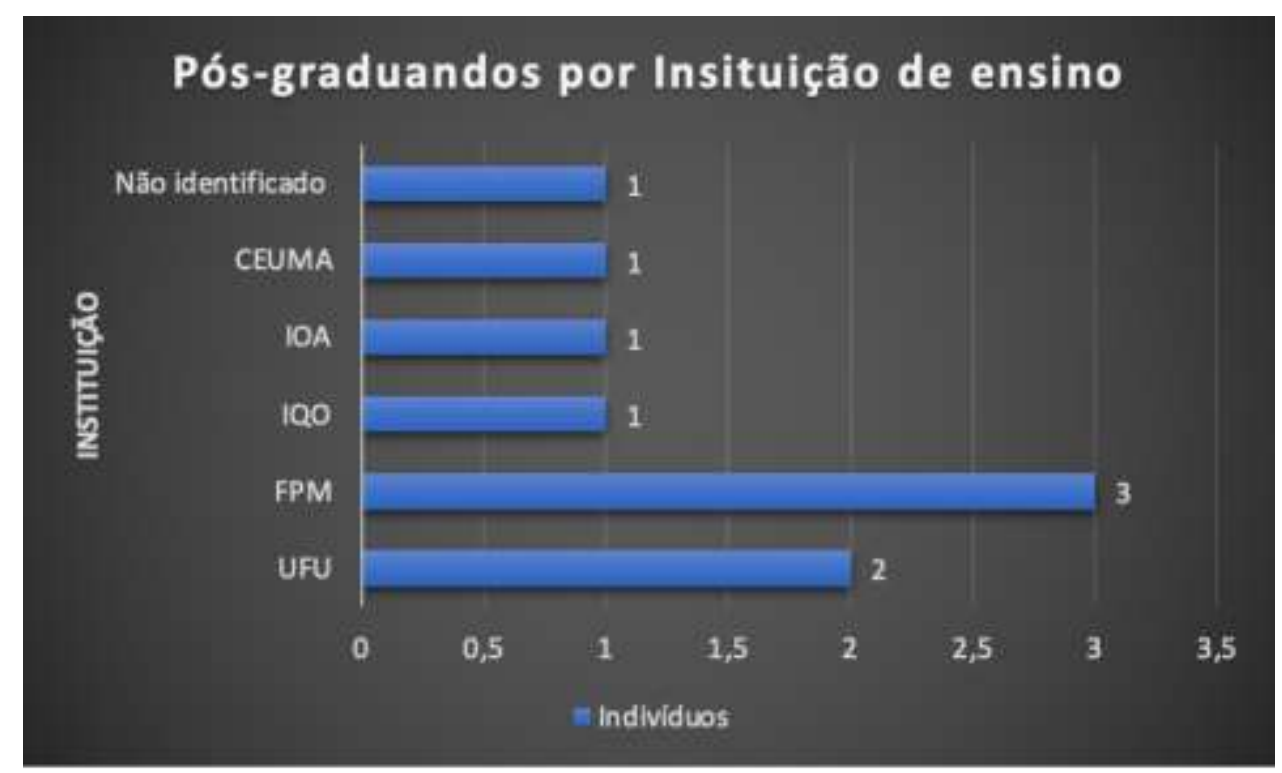

Fonte: Autores.

Tabela 1 - Distribuição dos participantes pelo período inscrito no curso de graduação e da pós-graduação.

\begin{tabular}{llll}
\hline Grau de instrução participantes \\
\hline Pós-graduação & \multicolumn{3}{l}{ Graduação } \\
\hline Endodontia & $3 \%$ & $1^{\circ}$ Período & $7 \%$ \\
\hline Prótese Fixa & $1 \%$ & $2^{\circ}$ Período & $1 \%$ \\
\hline Mestrado & $1 \%$ & $3^{\circ}$ Período & $12 \%$ \\
\hline Doutorado & $2 \%$ & $4^{\circ}$ Período & $2 \%$ \\
\hline Especialização & $1 \%$ & $5^{\circ}$ Período & $6 \%$ \\
\hline Estética & $1 \%$ & $6^{\circ}$ Período & $2 \%$ \\
\hline & & $7^{\circ}$ Período & $8 \%$ \\
\hline & & $8^{\circ}$ Período & $5 \%$ \\
\cline { 2 - 3 } & & $9^{\circ}$ Período & $42 \%$ \\
\hline & $10^{\circ}$ Período & $2 \%$ \\
\cline { 2 - 3 } & Indefinido & $5 \%$
\end{tabular}

Fonte: Autores.

No Gráfico 5 pode-se observar a porcentagem de indivíduos que que citaram que conhece a palavra halitose e sabe seu conceito. 
Gráfico 5 - Distribuição de indivíduos conforme o questionamento conhecer a palavra halitose e saber seu conceito.

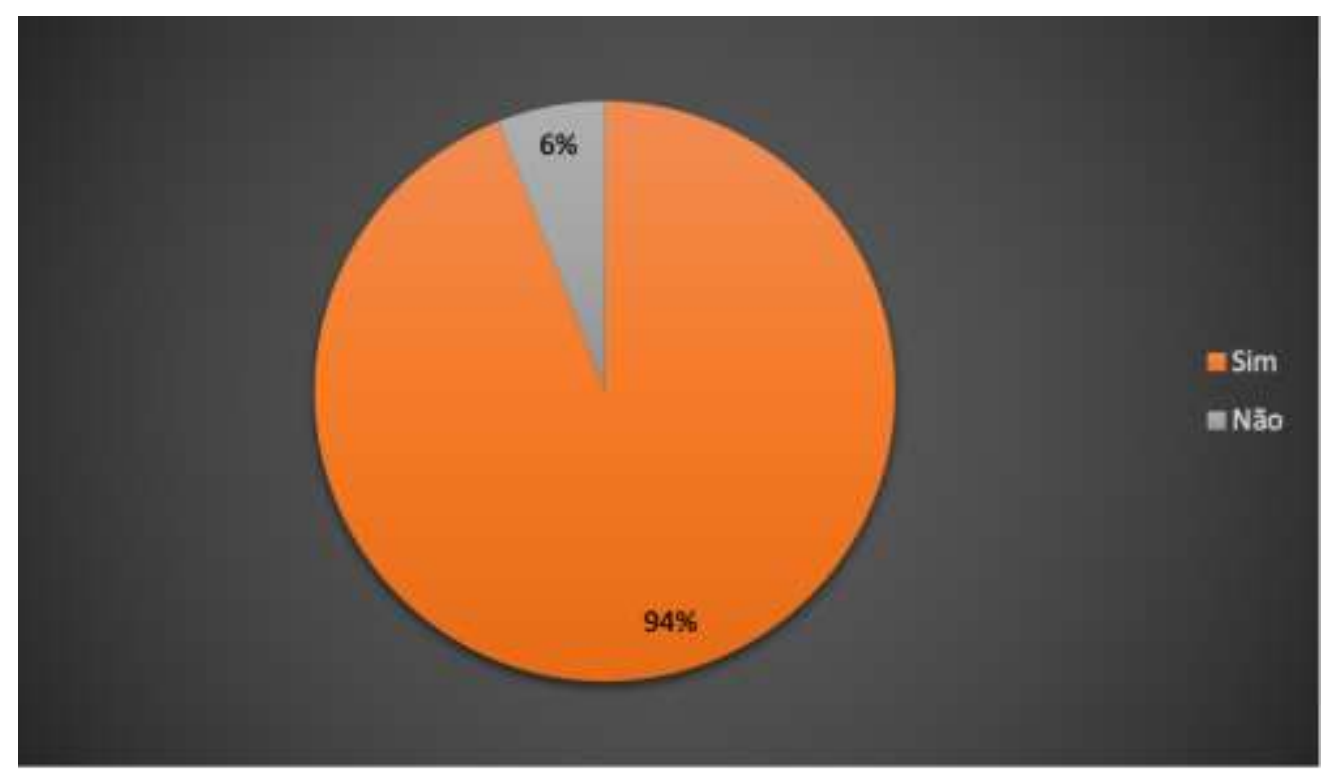

Fonte: Autores.

É perceptível que $94 \%$ dos indivíduos responderam sim enquanto $6 \%$ dos indivíduos responderam que não sabem o conceito da palavra halitose.

No Gráfico 6 mostra a porcentagem de indivíduos com relação a pergunta: “Você considera Halitose uma doença?

Gráfico 6 - Distribuição de indivíduos que consideram a halitose uma doença.

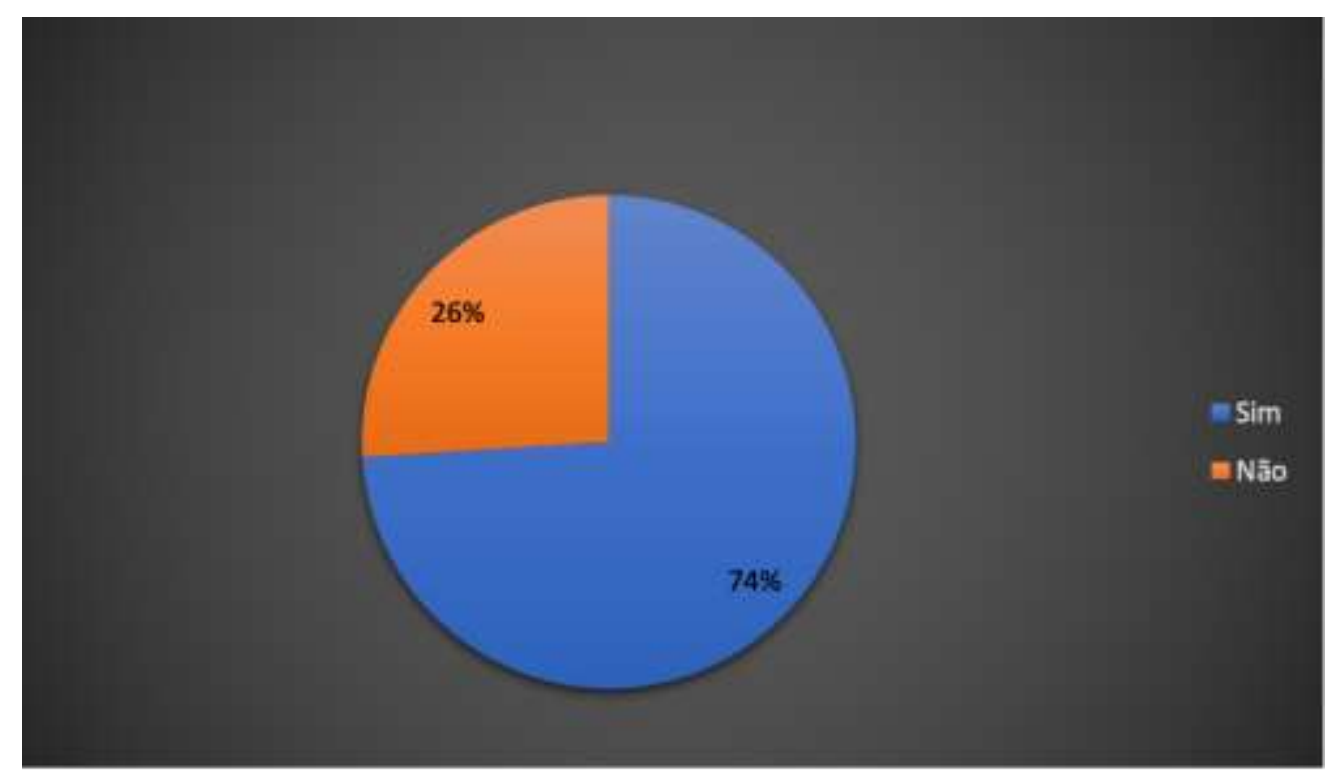

Fonte: Autores.

Observa-se que 74\% dos indivíduos responderam que consideram a halitose uma doença.

Com relação a saber diagnosticar a halitose, os dados estão representados no Gráfico 7. 
Gráfico 7 - Distribuição de indivíduos quanto a acreditar se sabem diagnosticar a halitose.

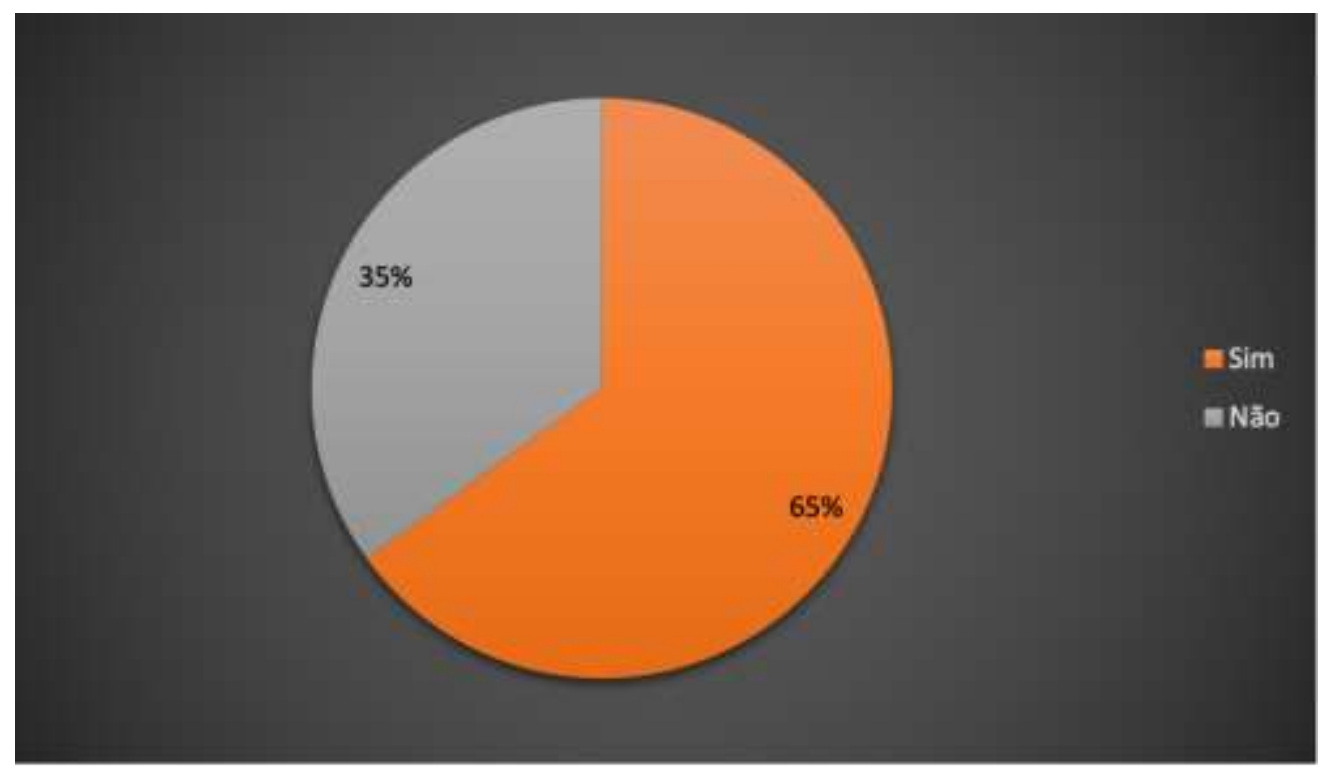

Fonte: Autores.

Percebe-se que a maioria dos participantes (65\%) afirmaram que acreditam saber diagnosticar halitose.

Os acadêmicos foram inqueridos ainda em relação a acreditar ou não na existência de cura para halitose (Gráfico 8).

Gráfico 8 - distribuição dos indivíduos distribuídos que acreditam ou não na cura da halitose.

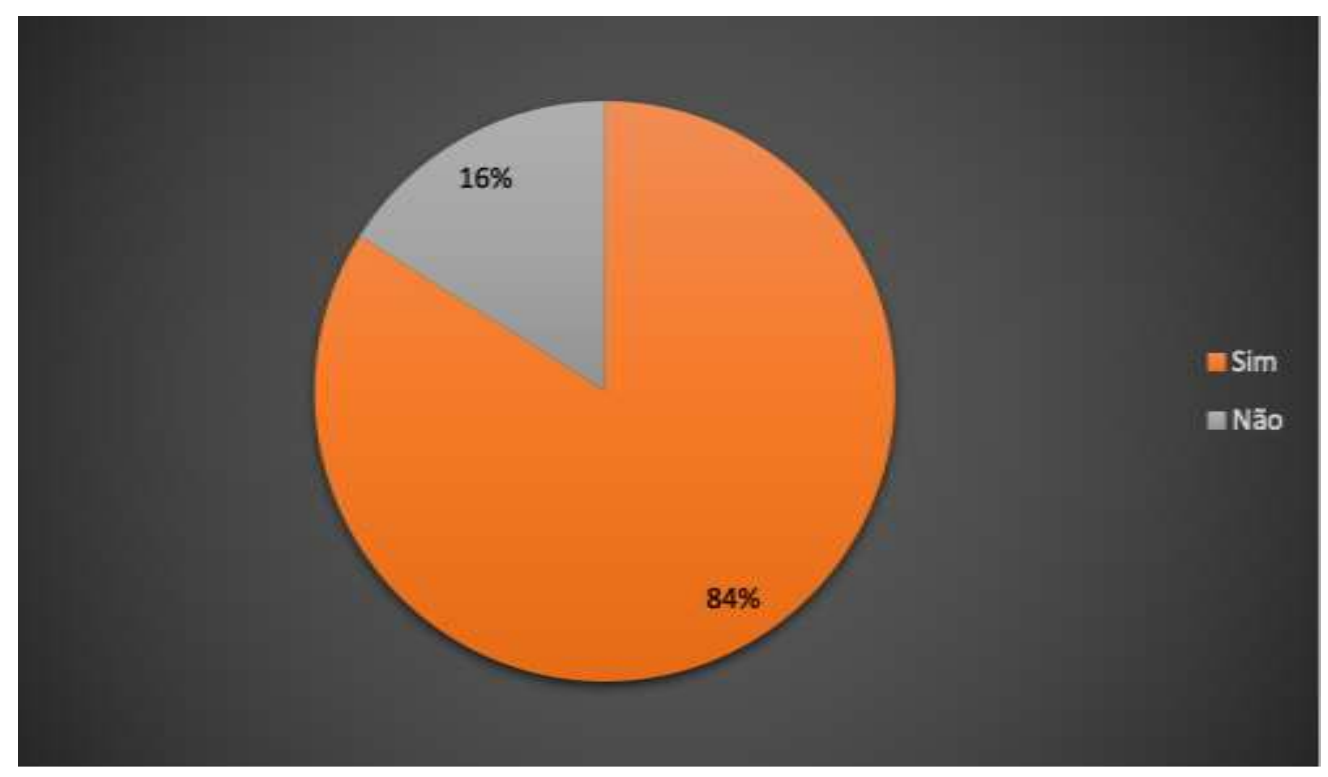

Fonte: Autores.

Conforme o Gráfico 8, observa-se que a grande maioria dos indivíduos (84\%) acreditam mencionaram que existe uma cura para a halitose.

No quesito saber como prevenir a halitose, as respostas dos participantes encontram-se descritas no Gráfico 9. 
Gráfico 9 - Distribuição de indivíduos que sabem ou não como prevenir a halitose.

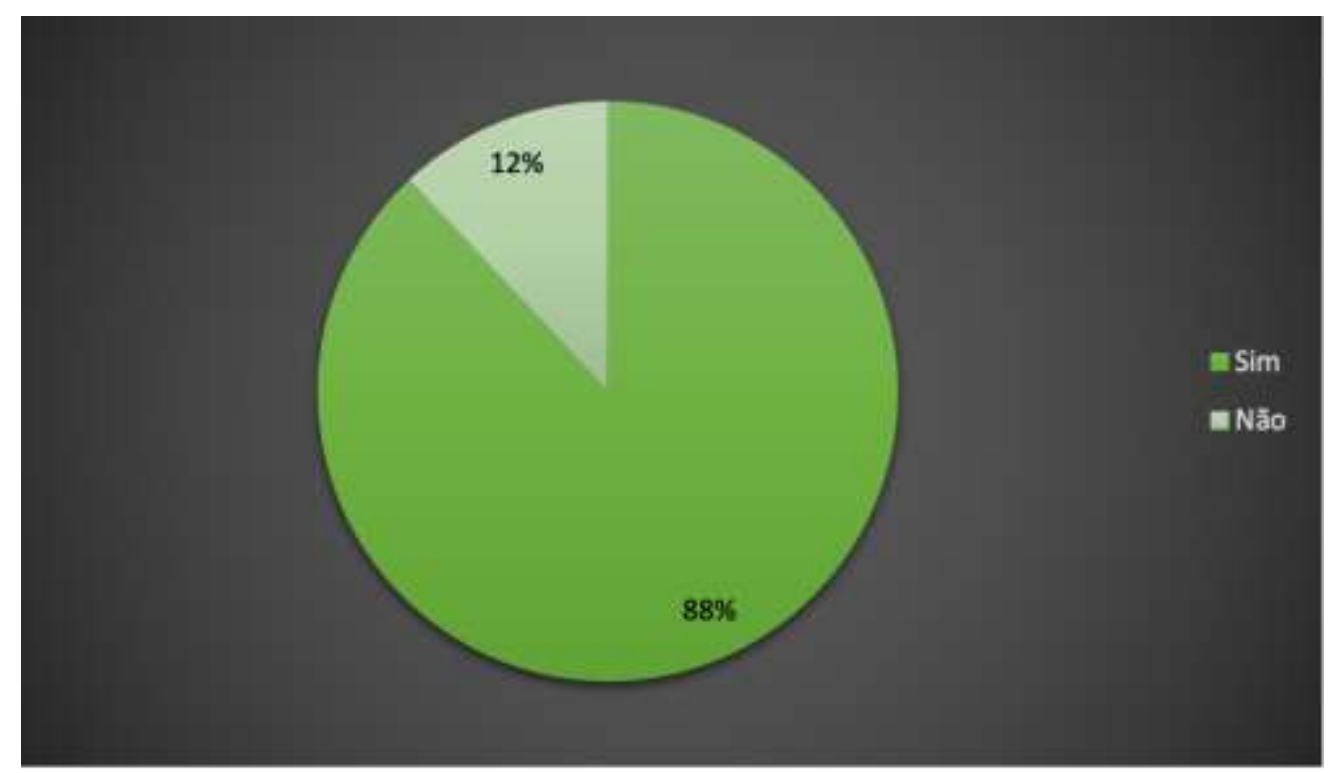

Fonte: Autores.

Nota-se que há uma porcentagem elevada (88\%) de indivíduos que afirmaram que sabem prevenir a halitose, já os outros $12 \%$ não tem conhecimento de como prevenir.

No questionário da pesquisa foram disponibilizadas quatro questões de múltipla escolha, onde o participante poderia marcar mais de uma alternativa conforme o seu conhecimento, sendo suas respostas dispostas nas tabelas 2, 3, 4 e 5 .

Na Tabela 2 foram propostas quatro alternativas acerca da definição da halitose na qual pode-se ver 61 demarcações na primeira alternativa, 8 na segunda, 35 na terceira e 14 na última.

Tabela 2 - Distribuição de definições para a halitose.

\begin{tabular}{ll}
\hline Definição & $\begin{array}{l}\text { Quantidade } \\
\text { de respostas }\end{array}$ \\
\hline $\begin{array}{l}\text { Odor desagradável persistente no ar exalado, que geralmente não é grave, chamado } \\
\text { comumente de mau hálito. }\end{array}$ & $61 \%$ \\
$\begin{array}{l}\text { Odor desagradável não muito persistente no ar exalado, que geralmente é grave, } \\
\text { chamado comumente de mau hálito. }\end{array}$ & $8 \%$ \\
$\begin{array}{l}\text { Odor desagradável persistente no ar exalado, que geralmente é grave, chamado } \\
\text { comumente de mau hálito ou "Halitosis" }\end{array}$ & $35 \%$ \\
A halitose também pode ser chamada de bafo ou mau hálito agudo. & $14 \%$ \\
\hline
\end{tabular}

Fonte: Autores.

Em questão a pergunta sobre causas possíveis da halitose, foram disponibilizadas 9 alternativas de escolha conforme a Tabela 3 . 
Tabela 3 -Disposição das possíveis causas da halitose.

\begin{tabular}{l|l}
\hline Causas possíveis da halitose & Quantidade de respostas \\
\hline Bucais & $60 \%$ \\
Fisiológica & $41 \%$ \\
Patológicas & $51 \%$ \\
Sistêmicas & $51 \%$ \\
Psicológicas & $16 \%$ \\
Multifatorial & $51 \%$ \\
Hereditários & $17 \%$ \\
Ambientais & $28 \%$ \\
Todas & $43 \%$ \\
\hline
\end{tabular}

Ao analisar os questionários, obteve-se as respostas sobre causas: bucais 60, fisiológicas 41, patológicas 51, sistêmicas 51, psicológicas 16 , multifatorial 51, hereditárias 17 , ambientais 28 , e a opção com todas as alternativas teve 43 respostas.

Foi perguntado sobre os tipos de halitose existentes, disponibilizando 8 opções de respostas aos participantes, sendo os resultados descritos na Tabela 4 .

Tabela 4 - Disposição dos tipos de halitose.

\begin{tabular}{l|l}
\hline Tipos de halitose existentes & Quantidade de respostas \\
\hline Halitose verdadeira & $39 \%$ \\
Halitose falsa & $24 \%$ \\
Halitose genuína & $32 \%$ \\
Pseudo-halitose & $45 \%$ \\
Halitofobia & $18 \%$ \\
Halotogia & $13 \%$ \\
Halitosis Iingual & $41 \%$ \\
Todas & $41 \%$ \\
\hline
\end{tabular}

Fonte: Autores.

Ficou evidente que as alternativas foram marcadas de acordo com a ordem crescente: pseudo-halitose 45, halitosis lingual 41, todas 41, halitose verdadeira 39, halitose genuína 32, halitose falsa 24, halitofobia 18, halitogia 13.

Foi perguntado sobre qual é a melhor opção de tratamento, disponibilizando assim quatro possibilidades de escolha (Tabela 5).

Tabela 5 - Classificação das melhores opções de tratamento.

\begin{tabular}{l|c}
\hline \multicolumn{1}{c|}{ Melhores opções de tratamento } & $\begin{array}{c}\text { Quantidade } \\
\text { de respostas }\end{array}$ \\
\hline Intervenções mecânicas e físicas no ambiente bucal & $21 \%$ \\
Intervenções mecânicas e químicas no ambiente bucal & $38 \%$ \\
Intervenções física e químicas no ambiente bucal & $22 \%$ \\
$\begin{array}{l}\text { Escovar os dentes e a língua depois de comer, usar fio dental pelo menos uma vez } \\
\text { por dia e substituir a escova de dente regularmente pode melhorar o mau hálito. }\end{array}$ & $79 \%$ \\
$\begin{array}{l}\text { Evitar alimentos conhecidos por causar mau hálito, como cebola e alho, também } \\
\text { pode ajudar }\end{array}$ & \\
\hline
\end{tabular}

Fonte: Autores.

É notório que a primeira opção teve 21 respostas, a segunda 38, a terceira 22 e a quarta 79 respostas.

No Gráfico 10, encontram-se os apontamentos dos participantes quanto ao estômago ser ou não responsável pelo mau 
hálito.

Gráfico 10 - Porcentagem de indivíduos que correlacionam o estomago com o mau hálito ou halitose.

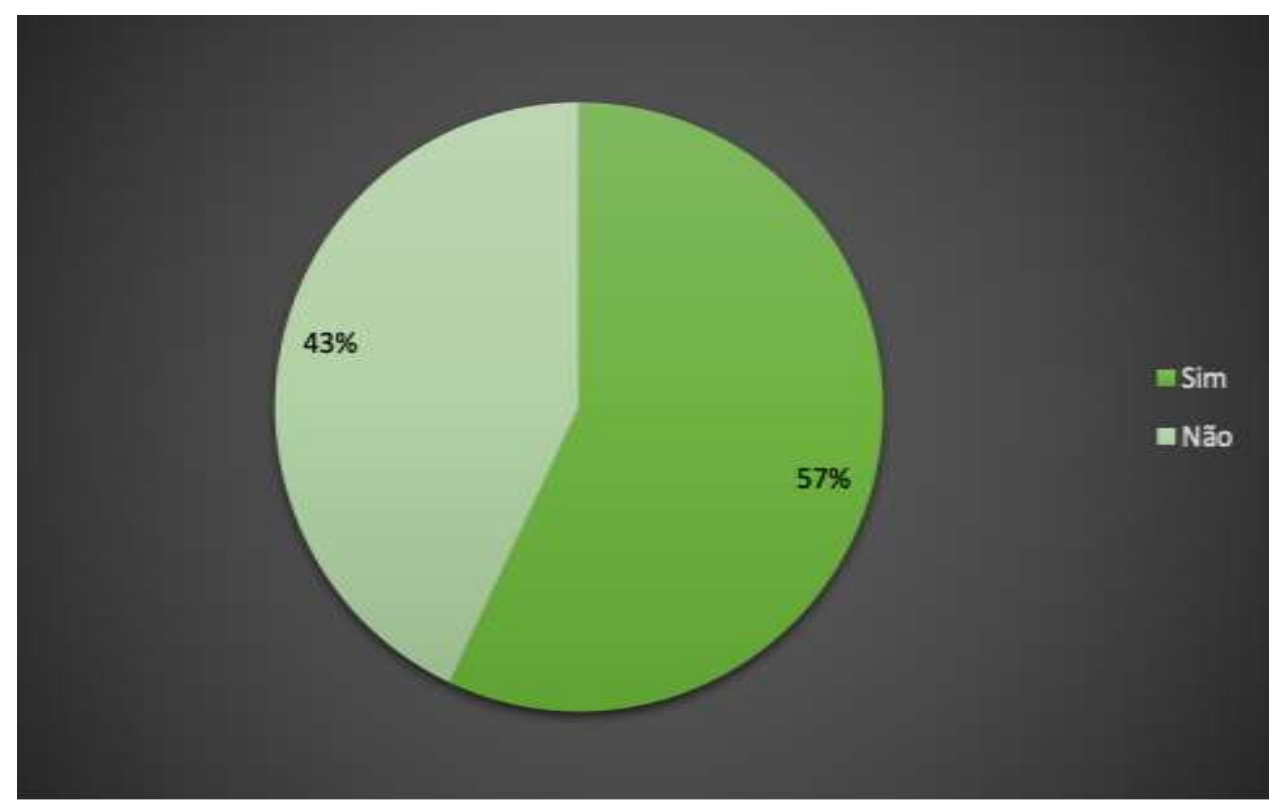

Fonte: Autores.

A porcentagem de indivíduos que acreditam que o responsável pelo mau hálito é o estômago é de $57 \%$ contra $47 \%$ não.

Acerca da pergunta sobre a existência ou não de aparelhos de diagnóstico da halitose o Gráfico 11 apresenta as respostas dos alunos.

Gráfico 11 - Disposição de indivíduos que acreditam que existem aparelhos para o diagnóstico da halitose.

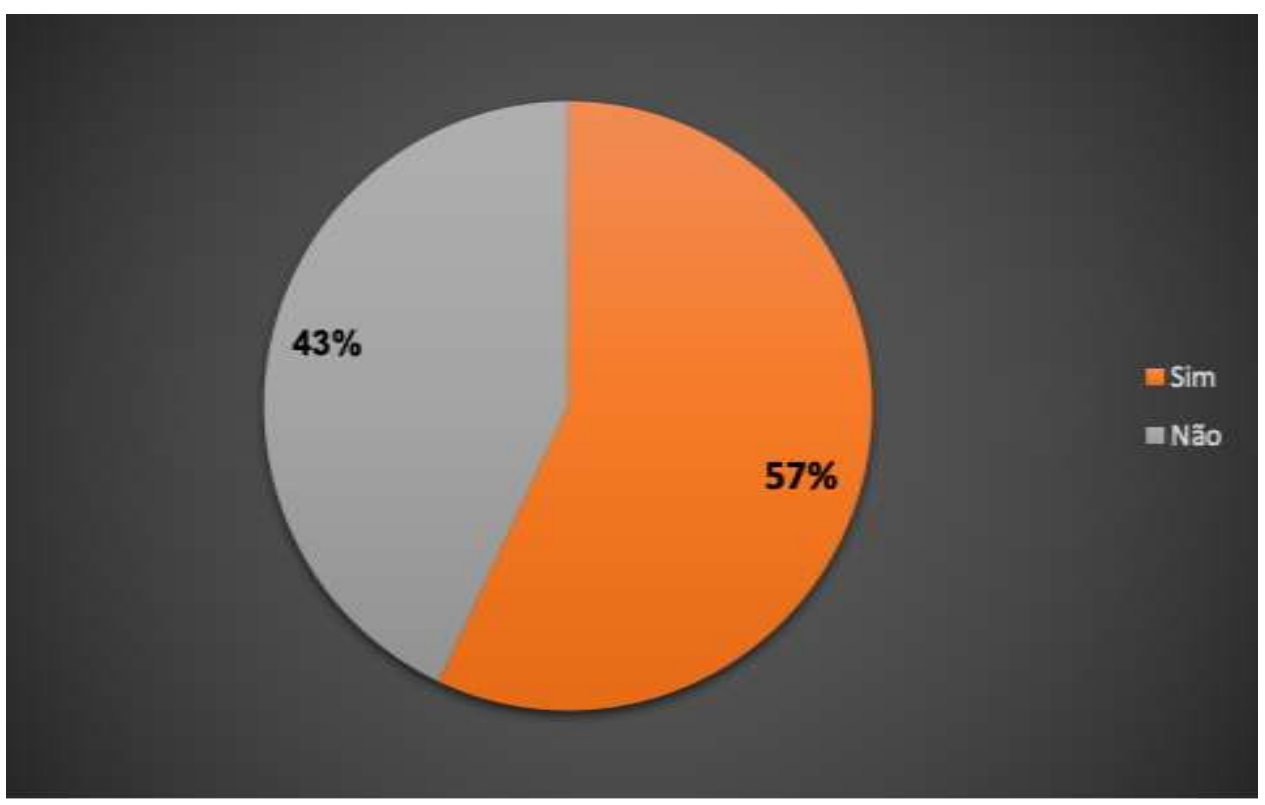

Fonte: Autores.

Observa-se que $43 \%$ não concordam que existem aparelhos para o diagnóstico da halitose e já 57\% concordam. 
No Gráfico 12 observa-se a porcentagem de indivíduos que assinalaram chicletes ou elixires, como capazes de eliminar a halitose.

Gráfico 12 - Distribuição de indivíduos quanto a considerar que chicletes ou elixires podem eliminar a halitose.

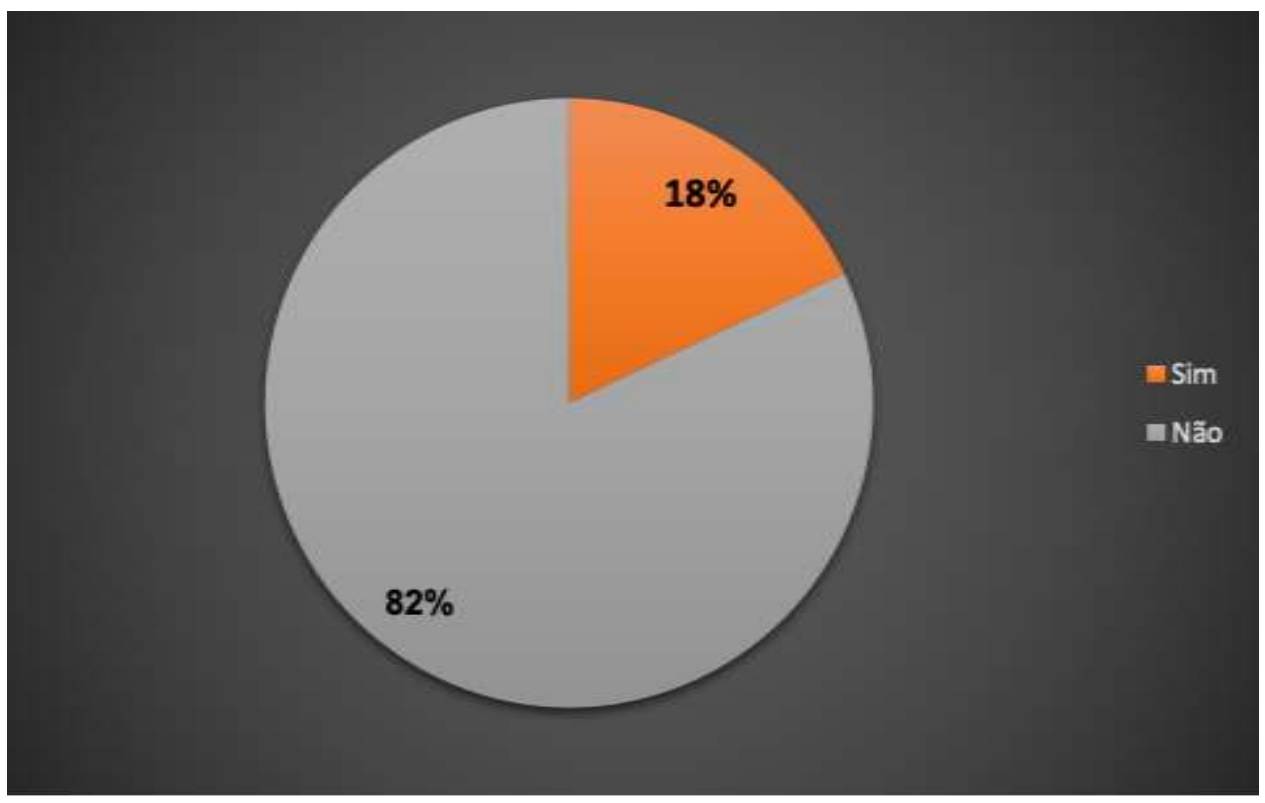

Fonte: Autores.

Dos respondentes, $18 \%$ disseram que esses produtos podem eliminar a halitose e $82 \%$ disseram que não.

Ao serem questionados sobre o fato da saliva comprometer o hálito obteve-se o seguinte resultado (Gráfico 13).

Gráfico 13 - Porcentagem de indivíduos que pressupõem que a saliva compromete o mau hálito.

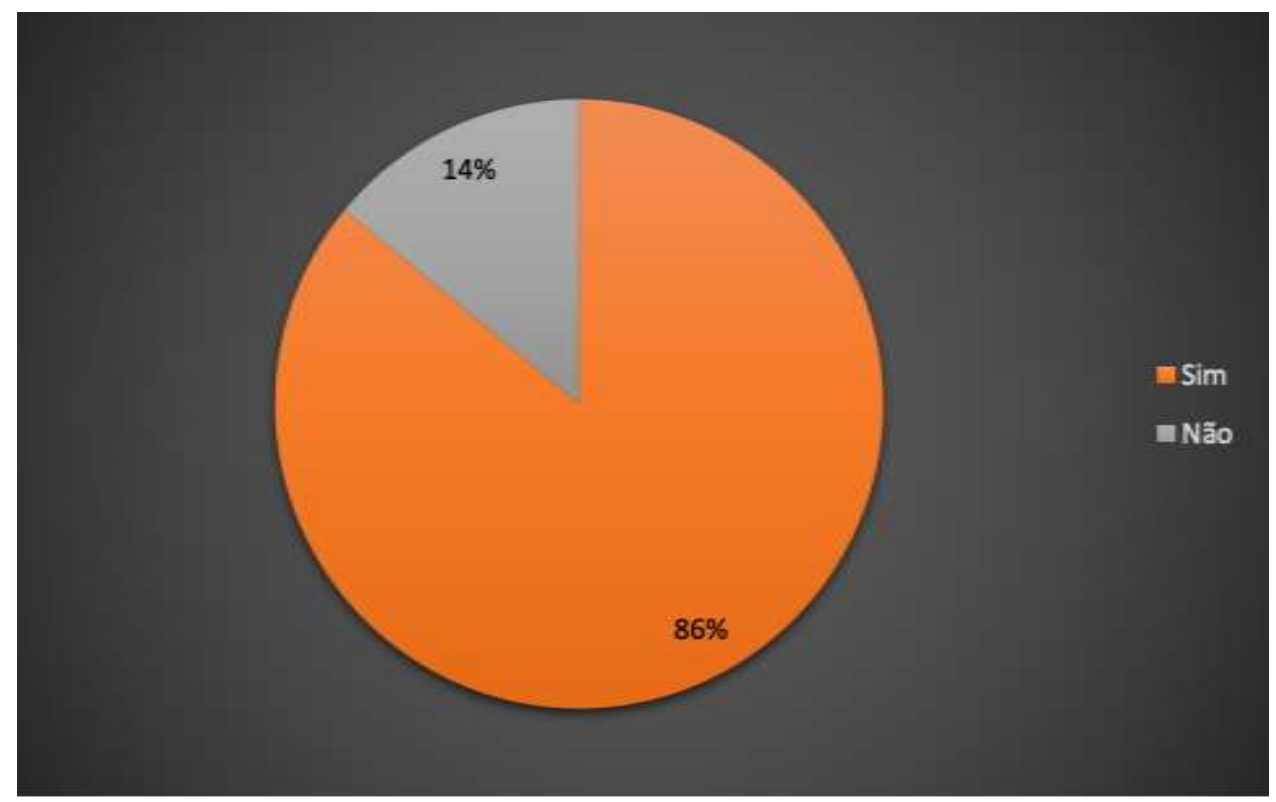

Fonte: Autores.

O gráfico anterior mostra que a maioria das respostas (86\%) mostram que os participantes concordam com a afirmação de que a saliva pode comprometer o hálito, e já 14\% responderam discordam dessa questão. 
No gráfico a seguir encontram-se descritas as respostas dos participantes quanto a sua opinião se o uso de colutórios (bochechos) com álcool afeta o hálito.

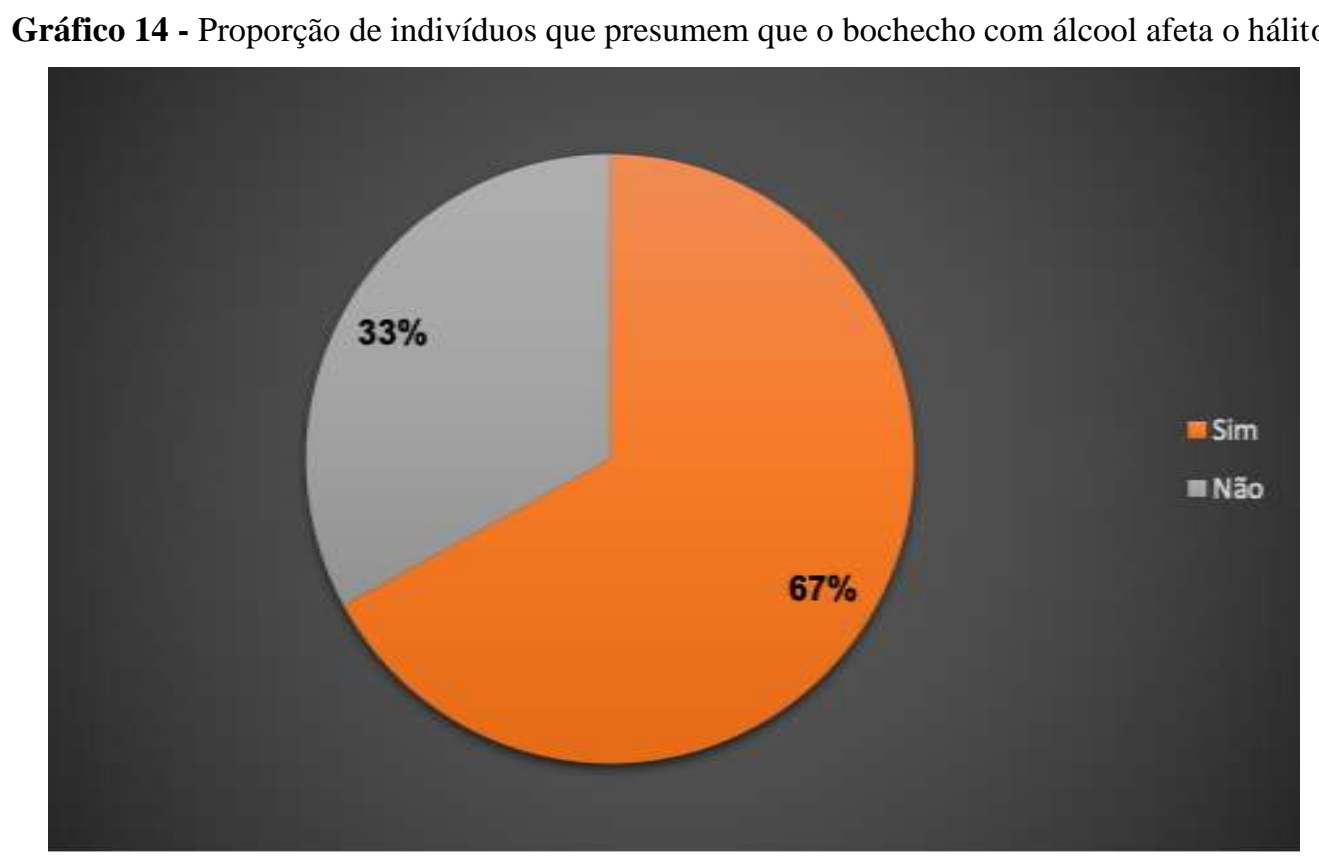

Fonte: Autores.

Pode-se analisar que quando perguntado se o uso de colutórios (bochechos) com álcool afeta o hálito, 67\% responderam que sim e $33 \%$ responderam que não.

No Gráfico 5 encontra-se a visão dos participantes quanto a relacionar o uso excessivo de medicamentos à halitose.

Gráfico 15 - Gráfico representativo de indivíduos que imaginam que o excesso de medicamentos causa halitose.

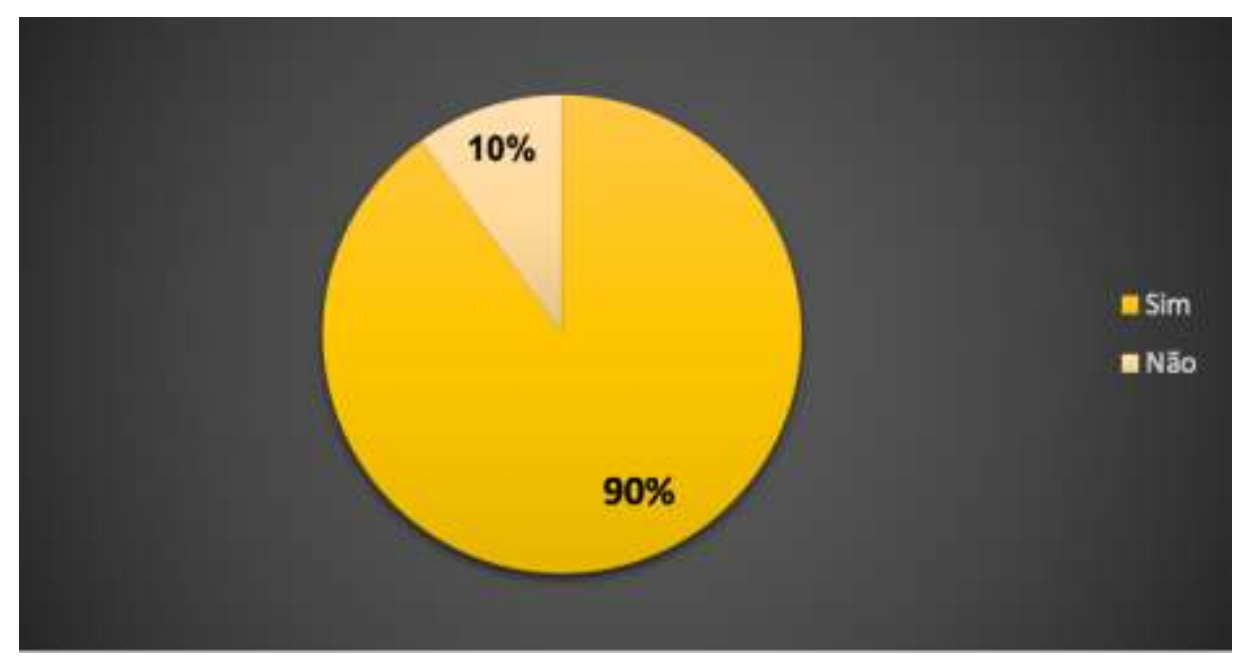

Fonte: Autores.

Nota-se que há uma porcentagem elevada (90\%) de indivíduos que possuem conhecimento sobre as causas do uso excessivo de medicamentos com relação a halitose, já os outros $10 \%$ não acham que o excesso seja um fator causador dessa condição.

O Gráfico 16 aponta em relação aos efeitos da bebida alcoólica sobre a halitose 
Gráfico 16 - Disposição de indivíduos que considera que a bebida alcoólica predispõe ao mau hálito.

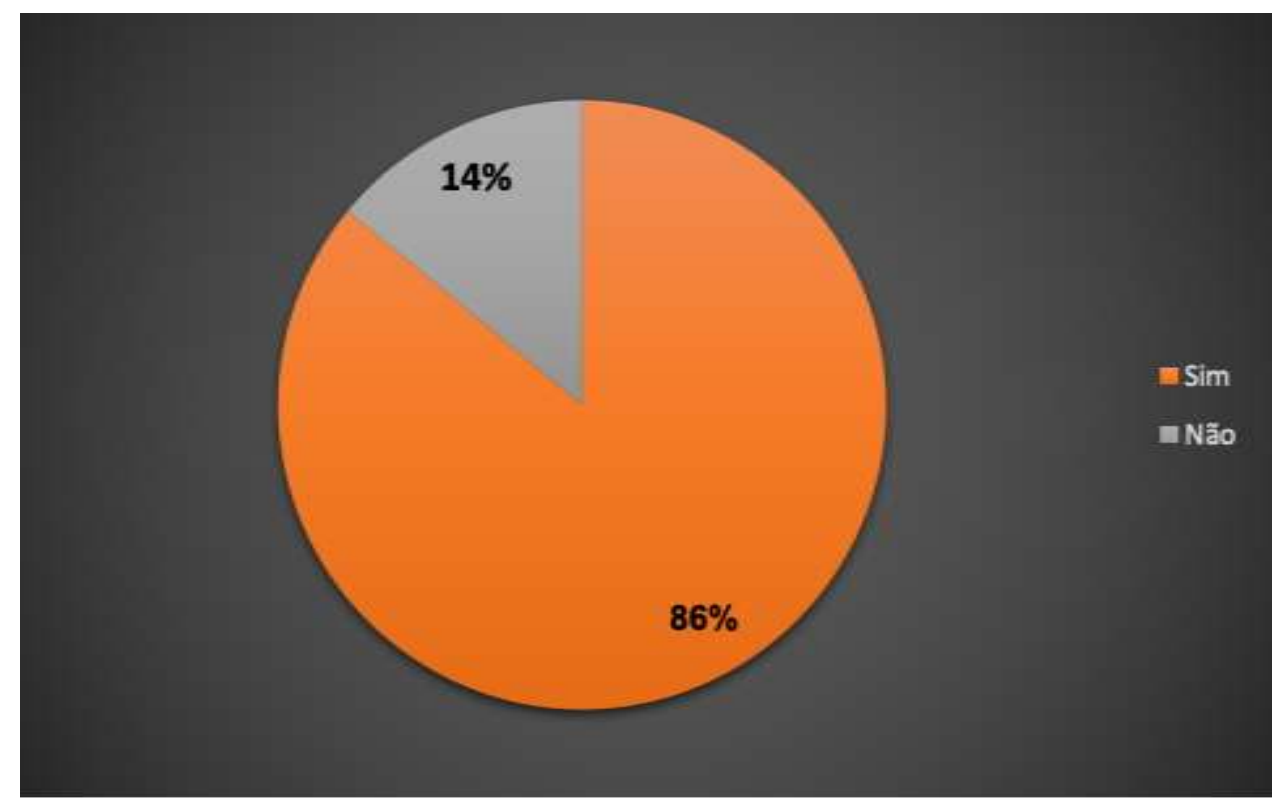

Fonte: Autores.

Observa-se que $86 \%$ dos indivíduos acreditam que existe uma predisposição de quem ao mau hálito por quem consome bebida alcoólica, enquanto $14 \%$ discordam.

No Gráfico 17, estão as respostas dos acadêmicos quando questionados se o consumo de tabaco pode estar relacionado ao mau hálito.

Gráfico 17 - Distribuição de pessoas que supõem que o fumo afeta o hálito.

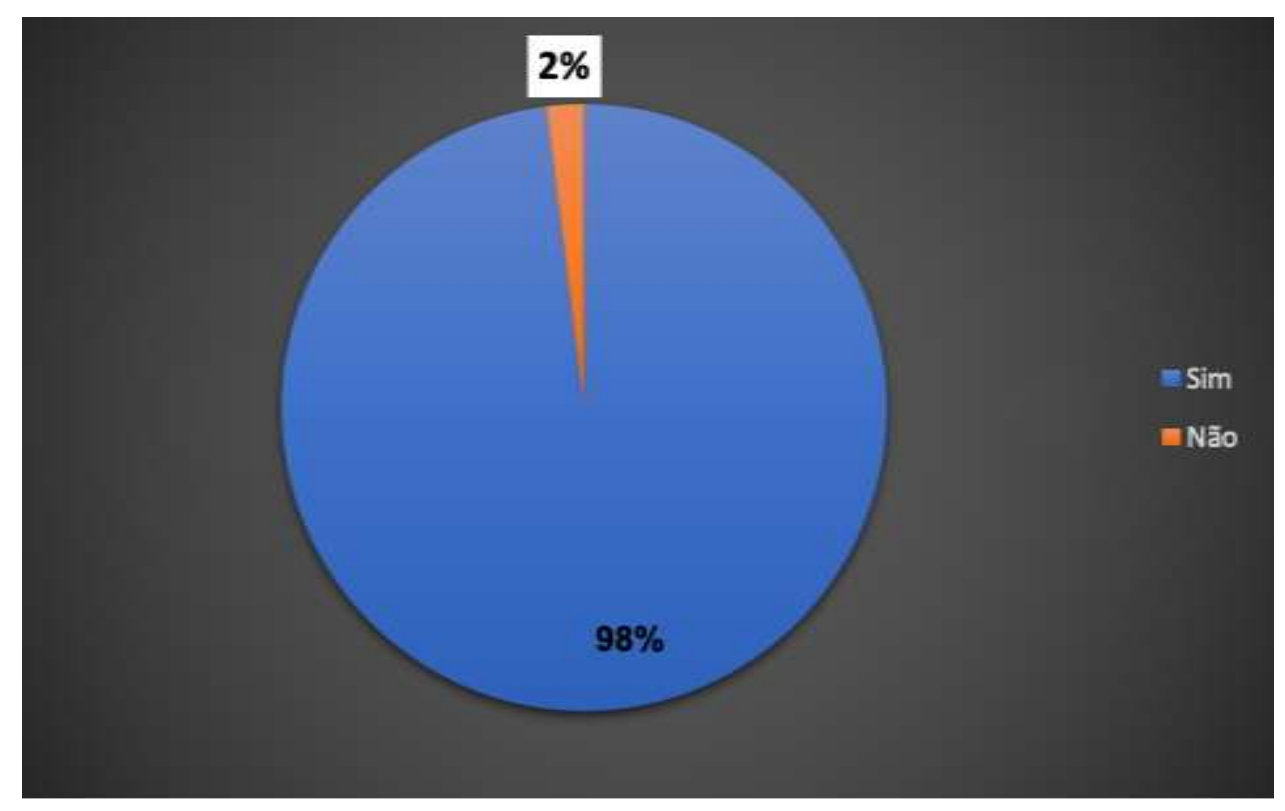

Fonte: Autores.

A grande maioria dos indivíduos, (98\%), acreditam que o tabaco provoca mau hálito, $2 \%$ responderam que não acreditam nessa relação. 


\section{Discussão}

Participaram do questionário on-line um total de 100 pessoas, onde 74 são do sexo feminino, 25 do sexo masculino e um indivíduo com sexo indefinido. De acordo com Vieira o sexo feminino é predominante a responder o questionário, pois a um interesse e frequência maior acesso às redes sociais (Vieira, Castro, \& Schucu Júnior, 2010).

Através dos gráficos pode-se ressaltar que a maior parte dos indivíduos responderam que sabem diagnosticar halitose. Para um bom diagnóstico de qualquer tratamento é necessário uma boa anamnese e exame clínico (Pereira et al., 2019).

Foi nítido a maior participação de graduandos da instituição FPM na pesquisa, isso se dá pelo fato de ter uma maior divulgação interna nesta instituição.

Em uma pesquisa com questionários aplicada por Castellanos et al. (2003) a discentes observou-se que a maioria dos participantes eram da instituição de ensino dos pesquisadores, corroborando assim para os resultados apresentados no gráfico 2, no qual 68 dos respondentes eram da FPM, a mesma dos pesquisadores.

A maior parte dos entrevistados responderam que sabem o conceito de halitose (94\%) conforme o gráfico 5 . Segundo a literatura a palavra halitose é oriunda do latim: “halitus" que significa ar expirado e "osis " uma alteração patológica (Abreu et al., 2011; Borges et al., 2018; Fagundes \& Oliveira, 2017; Ferreira, 2016, Pereira et al., 2019; Prata \& Macedo, 2019; Rodrigues, 2009), caracterizada por alteração ou condição anormal no hálito por odores desagradáveis emanados do ar expirado, independente do composto e origem, causas (Borges et al., 2018; Broek et al., 2008; Canever \& Nazário, 2019; Ciarcia et al., 2019; Domingos et al., 2011; Fagundes \& Oliveira, 2017; Mourão, 2014; Prata \& Macedo, 2019; Rodrigues, 2009). Já na tabela 2 onde foi disponibilizado as opções de múltipla escolha podendo marcar mais de uma opção sobre a definição de halitose foi observado que a primeira opção foi a mais escolhida com 61 marcações com a seguinte definição “Odor desagradável persistente no exalado, que geralmente não é grave, chamado comumente de mau hálito" que era a que estava com a definição mais correta. Porém em contrapartida alguns indivíduos marcaram outras opções de forma errônea, não sabendo assim o verdadeiro conceito de halitose.

Conforme Borges et al. (2018) e Domingos et al. (2011) a halitose ou o mau hálito não é considerado uma doença e sim um sinal que existe alguma desordem no indivíduo, podendo ser afetada por diversos fatores (Borges et al., 2018). Diferente da maioria das respostas do questionário em que $74 \%$ das pessoas consideram a halitose uma doença.

No gráfico 7 apresentado, a maior parte dos indivíduos pressupõe saber diagnosticar a halitose, e saber de fato diagnosticar é de suma importância para obter um tratamento preciso, no entanto anamnese e exame clínico são indispensáveis (Broek et al., 2008; Ferreira, 2016; Mourão, 2014; Pereira et al., 2019; Rodrigues, 2009). Porém quando foi perguntado se existem aparelhos de diagnóstico para a halitose (gráfico 11) apenas 57 pessoas responderam que existem aparelhos concordando assim com a literatura, mas 43 pessoas responderam que não existem, o que é considerado um número alto de indivíduos, pressupondo que alguns marcaram de forma errônea que sabem sobre como diagnosticar a halitose.

Teste organoléptico, cromatografia gasosa e halímetro são métodos usados para diagnosticar de formas subjetivas e objetivas (Broek et al., 2008; Kraether Neto et al., 2019; Leandrin et al., 2015, Pereira et al., 2019; Silveira, 2019). Sendo o mais utilizado teste organoléptico, devido a sua praticidade e baixo custo (Kraether Neto et. al., 2019; Mourão, 2014; Pereira et al., 2019). Cromatografia gasosa é considerado o método mais confiável, porém custo alto (Bicak, 2018; Mourão, 2014; Prata \& Macedo, 2019; Rodrigues, 2009, Vasconcelos et al., 2011). O Halímetro também é de fácil utilização e analisa a quantidade de enxofre presente no hálito através de um aparelho rápido e objetivo (Mourão, 2014; Vasconcelos et al., 2011).

Como é sabido que a halitose não é uma doença (Borges et al., 2018), com isso também a palavra cura não é apropriada e sim é através do controle que se tem uma melhora da halitose com um correto tratamento de acordo com o tipo de halitose (ABHA, 2021). Entretanto, mostra-se que grande parte da população da pesquisa acredita que existe cura $84 \%$ (gráfico 8), se opondo a literatura. 
De acordo com Rodrigues (2009) as formas preventivas mais eficientes para evadir a halitose compreende na diminuição das bactérias da cavidade oral, por meio de uma escovação eficaz, limpeza da língua diariamente através de raspadores, uso de dentifrícios com flúor, podendo ainda ser utilizados elixires antimicrobianos.

Em uma pesquisa feita por Miotto, Boning e Barcellos (2014) a maioria dos entrevistados afirmaram que a escovação é o mais eficaz para prevenir a halitose, corroborando assim com os resultados do gráfico 9 e com a literatura.

Já para Abreu et al. (2011) é preciso conhecer as causas possíveis da halitose para que se possa prevenir. Ademais, como a maioria afirma saber sua forma de prevenção (gráfico 9), porém os dados da tabela mostram uma dispersão das respostas em relação às causas do mau hálito, ou seja, não podemos afirmar com convicção que os $88 \%$ sabem a melhor forma de prevenir essa condição do organismo.

Em conformidade com a literatura a halitose é uma condição de etiologia multifatorial (Bicak, 2018, Borges et al., 2018; Canever \& Nazário, 2019; Domingos et al., 2011; Fagundes \& Oliveira, 2017; Kraether Neto et al., 2019; Leandrin et al., 2015; Mourão, 2014; Prata \& Macedo, 2019). Com causas fisiológicas, patológicas, sistêmicas, psicológicas e a sua principal causa é a relacionada com a cavidade bucal com mais de 80\% dos casos relatados (Borges et al., 2018; Broek et al., 2008; Canever \& Nazário, 2019; Dal Rio et al., 2007; Domingos et al., 2011, Leandrin et al., 2015; Mourão, 2014; Pereira et al., 2019; Rodrigues, 2009; Sombié et al., 2018). Logo confirma-se que a maior parte dos participantes possuem conhecimento acerca das causas, não obstante alguns tiveram certa dificuldade em discernir as principais etiologias e se equivocaram. Visto que a halitose não é causada por fatores hereditários e ambientais.

Vários estudos apontam que existem três categorias de divisões para a halitose: halitose verdadeira ou genúina, pseudo-halitose e halitofobia, podendo ainda dividir a halitose verdadeira em halitose fisiológica e patológica (Borges et al., 2018; Domingos et al., 2011; Mourão, 2014, Prata \& Macedo, 2019; Rodrigues, 2009; Silveira, 2019, Vasconcelos et al., 2011). Em contrapartida com a base de dados científicos, a maior parte dos participantes não possuem conhecimento acerca dos tipos de halitose, entretanto houve uma parcela significativa que justificou a literatura. Ademais que, os tipos halitose não incluem halotogia, haliosis lingual e halitose falsa.

Inúmeros materiais científicos afirmam que deve ser traçado um protocolo de tratamento específico para cada tipo de indivíduo que apresenta essa condição (Borges et al., 2018; Mourão, 2014,). Entretanto pelo fato de que mais de 80\% dos casos tem causas relacionadas a cavidade oral, o tratamento consiste em diminuir os compostos voláteis de enxofre e outras substâncias desagradáveis, através de intervenções mecânicas e químicas (Faber, 2009; Fagundes \& Oliveira, 2017; Mourão, 2014; Rodrigues, 2009), além de uma higiene oral eficaz independentemente do tipo de halitose (Mourão, 2014). Comprovando assim, aproximadamente $73 \%$ das respostas estão de acordo com as pesquisas científicas.

Do total pesquisado $57 \%$ acreditam que é o estômago o responsável pela a halitose, constituindo assim um equívoco pelos participantes, pois segundo Leandrin et al. (2015) a halitose está dificilmente associada ao aparelho digestivo, somente em algumas ocasiões raras de eructações gástricas (Leandrin et al., 2015; Miotto et al., 2014).

Diversos estudos afirmam que existem alguns aparelhos que podem fazer o diagnóstico da halitose, dentre eles a cromatografia gasosa (através de quantificações de CSV) e o halímetro ou monitores de sulfeto (quantidade de enxofre presente no hálito). Apesar da maioria (57\%) apontar que existem aparelhos, confirmando os estudos, a porcentagem dos que não conhecem (43\%) é bastante significativa, o que mostra a necessidade de trazer à sociedade conhecimento sobre os aparelhos existentes.

De acordo com a literatura os pacientes com halitose, tentam mascarar odores, através de, pastilhas (chiclete), elixires e sprays (Ferreira, 2016; Mourão, 2014; Pereira et al., 2019). Entretanto, o uso de chiclete pode ser prejudicial a ATM, além disso, possui açúcar em sua composição o que pode desencadear um processo cariogênico, porém pode estimular o fluxo salivar (Ferreira, 2016; Mourão, 2014). Em questão aos elixires segundo Rodrigues (Rodrigues, 2009), o seu uso diário com 
clorexidina e triclosan diminui o hálito matinal pois reduzem a quantidade de bactérias presentes na cavidade bucal.

Contrapondo assim a ciência $82 \%$ das pessoas acreditam que o chiclete e elixires não eliminam o mau hálito. Entretanto deve-se ficar atento à composição química dos produtos utilizados e procurar um profissional da área, pois nem todos trazem benefícios à saúde.

De acordo com Mourão a saliva tem grande importância na halitose, tem a capacidade de limpeza natural da cavidade oral (Mourão, 2014). A redução do fluxo salivar predispõe a construção do biofilme da cavidade e da língua, consequentemente haverá uma intensificação do mau hálito. Durante a mastigação há aumento do fluxo salivar e com isso ocorre a limpeza da cavidade oral (Mourão, 2014; Borges et al., 2018). Assim é evidente que a saliva exerce influência na halitose, logo grande parte dos indivíduos (86\%) respondentes do questionário estão coerentes com as obras acadêmicas mencionadas.

De acordo com o gráfico 14, a maior parte dos indivíduos responderam que os enxaguantes bucais contendo álcool podem sim alterar o hálito. É sabido que esses enxaguatórios contendo álcool é prejudicial à saúde da cavidade oral, podendo causar um ressecamento da mucosa oral e até mesmo uma sensação de ardência, ou seja, alterando a microbiota bucal (ABHA, 2021; Miotto et al., 2014).

Alguns autores afirmam que o uso de medicamentos promove a halitose, pelo fato de que algumas substâncias que os constituem podem alterar a sensação de gosto e olfato, ocasionando também a redução do fluxo salivar e xerostomia (Mourão, 2014; Rodrigues, 2009; Torsten et al., 2017). Dessa maneira as respostas obtidas no gráfico 15, em que 90\% dos indivíduos afirmaram sim, está de acordo com os achados na literatura.

Vários estudos indicam que a ingestão de bebida alcoólica potencializa o aparecimento e o desenvolvimento da halitose. A sua ingestão leva à desidratação da mucosa oral, aumenta a descamação epitelial, altera a microflora intestinal, promove uma fermentação odorífera que leva à produção da halitose (Dal Rio et al., 2007; Fagundes \& Oliveira, 2017; Ferreira, 2016; Mourão, 2014; Prata \& Macedo, 2019; Rodrigues, 2009).

Por conseguinte, $86 \%$ dos resultados afirmam o potencial que a bebida alcoólica tem sobre o desenvolvimento da halitose, reafirmando as bases teóricas.

Estudos mostram que o uso de tabaco corrobora com a intensificação da halitose. O fumo, quer inalado ou exalado, provoca um aumento do mau hálito e agride a mucosa descamando e reduzindo o fluxo salivar, por último aumenta o biofilme da cavidade oral e lingual, consequentemente desenvolvimento de doenças periodontais, elevando os níveis de CSV (Dal Rio et al., 2007; Fagundes \& Oliveira, 2017; Ferreira, 2016; Mourão, 2014; Prata \& Macedo, 2019; Rodrigues, 2009).

Dessa forma, a maioria dos indivíduos (98\%) da pesquisa demonstrou ter conhecimento do assunto, ou seja, sustentando a ideia de que o tabaco prejudica o hálito de quem o consome. Assim, validamos o que foi encontrado em diversos artigos acadêmicos do trabalho.

\section{Conclusão}

Perante ao exposto a halitose é uma condição de etiologia multifatorial que afeta milhares de pessoas mundialmente com prevalência em ambos os sexos. Para o sucesso no tratamento é necessário um bom e correto diagnóstico, para saber qual o tipo de halitose e assim tratá-la da maneira adequada.

Apesar da sua grande importância na saúde do indivíduo boa parte dos pesquisados acreditam que sabem sobre a halitose, entretanto foi observado que a maioria não tem o conhecimento básico e não sabem as causas da halitose para diagnosticar o problema. Sugere-se que em trabalhos pósteros sejam feitos maiores estudos a fim de facilitar um correto diagnóstico e tratamento. Assim também espera a inserção mais ativa e expressiva da halitose nas disciplinas de patologia e estomatologia dos cursos de graduação em Odontologia visando capacitar os futuros profissionais. 


\section{Referências}

Abreu, A. C., Domingos, P. A. S., \& Dantas, A. A. R. (2011). Causas e sintomas da halitose: estudo do conhecimento entre pacientes do curso de odontologia. Rev odontol Univ Cid São Paulo, 23(1), 30-41.

Araújo, R. F. S. B., Sousa, M. M, \& Lima, K. C. (2015). Concentração alcoólica de antissépticos bucais comercializados no Brasil no início da segunda. Rev Ciênc Plural. 1(3), 26-37.

Associação Brasileira de Halitose-ABHA, (2008). O Mau Hálito e a qualidade de Vida: pesquisa verificou que quem tem hálito alterado prefere ser avisado. Natal.

Associação Brasileira de Halitose-ABHA. (2009). O Mau Hálito e o Profissional da Área de Saúde. Natal.

Associação Brasileira de Halitose-ABHA. (2021). Quebrando Tabus: remédio para mau hálito. Natal.

Bicak, D. A. (2018). A current approach to halitosis and oral malodor. Opean dent j. 12:322-30.

Borges, H. F. C., Santiago, L. F. P., Santos, K. S. S., Silva, T. F. N., Mendonça, I. C. G., \& Moura, M. (2018). Halitose: uma condição multifatorial que tem tratamento. REAS/EJCH. (18)e82, 1-7.

Broek, A. M., Feenstra, L., \& Baat, C. (2008). A review of the current literature on management of halitosis. Oral dis. 14(1), 30-39.

Canever, L. M., \& Nazário, M. V. (2019). Métodos de diagnóstico para halitose de origem bucal: revisão de literatura. Trabalho de Conclusão de Curso de Graduação em Cirurgião Dentista, Universidade do Extremo Sul Catarinense, Criciúma.

Castellanos, M. E. P., Fagundes, T. L. Q., Nunes, T. C. M., Gil, C. R. R., Pinto, I. C. M., Belisário, S. A. et al. (2003). Estudantes de graduação em saúde coletiva: perfil sociodemográfico e motivações. Ciência e Saúde coletiva. 18(6),1657-1666.

Ciarcia, A. C. C. M., Gonçalves, M. L. L., Horliana, A. C. R. T., Suguimoto, E. S. A., Araujo, L., Laselva, A. et al. (2019). Action of antimicrobial photodynamic therapy with red leds in microorganisms related to halitose: controlled and randomized clinical trial. Med. 98(1), e13939.

Dal Rio, A. C. C., Nicola, E. M. D., \& Teixeira, A. R. F. (2007). Halitose: proposta de um protocolo de avaliação. Rev Bras Otorrinolaringol. 73(6), 835-842.

Domingos, P. A. S., Abreu, A. C., Dantas, A. A. R., \& Oliveira, A. L. B. M. (2011). Halitose: limitando a qualidade de vida. Rev odontol Univ Cid São Paulo, 23(2), 171-181.

Faber, J. (2009). Halitose. Rev Dent Press Ortod Ortop Facial. 14(3), 14-15.

Fagundes, B. O., Oliveira, V. B. (2017). Halitose, uma abordagem dos fatores locais: Saburra lingual e doença periodontal. Artigo de graduação em Odontologia, São Lucas Centro universitário, Porto Velho.

Falcão, D. P. (2005). Avaliação da viscosidade salivar e sua relação com a halitose. Dissertação de Mestrado, Universidade de Brasília, Brasília.

Ferreira, J. P. A. (2016). Halitose: da etiologia ao tratamento. Dissertação de Mestrado em Medicina Dentária, Universidade Fernando Pessoa, Porto.

Kraether Neto, L., Schmidt Maas, J. R., \& Pellicioli, F. (2019). Estudo longitudinal da halitose por meio da cromatografia gasosa. RFO, 24(2), 204-10.

Leandrin, T. P., Boeck, E. M., Ricci, H. A, Andrade, M. F, \& Cerqueira-Leite J. B. B. (2015). Avaliação da percepção pessoal em relação à condição de halitose e confirmação clínica. Rev Odontol UNESP, 44(5), 299-304.

LeBel, G., Haas B., Adam, A. A., Veilleux M. P., Lagha, A. B., \& Grenier, D. (2017). Effect of cinnamon (Cinnamomum verum) bark essential oil on the halitosis-associated bacterium Solobacterium moorei and in vitro cytotoxicity. Arch oral biol. 83:97-104.

Miotto, M. H. M. B., Boning, N. L. H., Barcellos, L. A. (2014). Percepção de halitose entre acadêmicos de Odontologia. Brazilian Research in Pediatric Dentistry and Integrated Clinic. 14(3), 3-13.

Mourão, E. F. (2014). Prevalência da halitose, fatores fisiopatológicos associados: uma proposta de avaliação. Dissertação de mestrado em Medicina Dentária, Universidade Católica Portuguesa, Viseu.

Pereira, I., Marcelo, S., André, S., \& Lousan, N. (2019). Abordagem da halitose nos cuidados de saúde primários: proposta de um protocolo de atuação. Rev Port Med Geral Fam. 35, 61-67.

Prata, L. R., \& Macedo, G. O. (2019). Halitose: uma revisão de literatura. Trabalho de conclusão de curso, Universidade Tiradentes, Aracaju.

Rodrigues, A. S. B. (2009). Halitose: cruzamento de variáveis fisiopatológicas numa perspectiva clínica Monografia de Graduação em Medicina Veterinária, Universidade Fernando Pessoa, Porto.

Roldán, S., Herrera, D., \& Sanz, M. (2003). Biofilms and the tongue: therapeutical approaches for the control of halitosis. Clin Oral Invest. 7 , $189-97$.

Silveira, J. O. (2019). Halitose: adaptação trascultural, validação do questionário e impacto emocional na qualidade de vida dos indivíduos. Tese de Doutorado em Odontologia, Universidade Federal de Minas Gerais, Belo Horizonte.

Sombié, R., Tiendrébéogo, A. J. F., Guiguimdé, W. P. L., Guingané, A., Tiendrébéogo, S., Ouoba, K. et al. (2018). Halitose: approches diagnostiques et thérapeutiques pluridisciplinaires [Halitosis: multidisciplinary diagnostic and therapeutic approaches]. Pan Afr med j. 30:201. 
Research, Society and Development, v. 10, n. 13, e429101321707, 2021

(CC BY 4.0) | ISSN 2525-3409 | DOI: http://dx.doi.org/10.33448/rsd-v10i13.21707

Tolentino, E. S. (2009). Avaliação do pH da saliva e da saburra lingual antes e após a utilização de soluções enxaguantes orais e sua relação com parâmetros de halitose. Dissertação de mestrado em Odontologia, Faculdade de Odontologia de Bauru da Universidade de São Paulo, Bauru.

Torsten, G., Gómez-Moreno, G., \& Aguilar-Salvatierra, A. (2017). Drug-related oral malodour (halitosis): a literature review. Eur rev med pharmacol sci. 21, 4930-3494.

Vasconcelos, L. C. S., Veloso, D. J., Cunha, P. A. S. M. A., \& Vasconcelos, L. C. (2011). Clinical knowledge of dentists and physicians on the diagnosis and treatment of the patient complaining of halitosis. Rev Odonto Cienc., 26(3), 232-237.

Vieira, H. C., Castro, A. E., \& Schucu Júnior, V. F. (2010). O uso de questionários via e-mail em pesquisas acadêmicas sob a ótica dos respondentes. Anais do SEMEAD, XII São Paulo. 